Cómo citar este trabajo: Larrubia Vargas, R., Navarro Rodríguez, S. R., \& Natera Rivas, J. J. (2019). Sobre los factores de diferenciación de la diversidad rural y las opciones de su clasificación: ensayo metodológico en la provincia de Málaga. Boletín de la Asociación de Geógrafos Españoles, 81, 2697, 1-45. http://dx.doi.org/10.21138/bage.2697

\title{
Sobre los factores de diferenciación de la diversidad rural y las opciones de su clasificación: ensayo metodológico en la provincia de Málaga
}

On the factors of rural diversity differentiation and the options of its classification: methodological essay in the province of Malaga

\author{
Remedios Larrubia Vargas \\ rlarrubia@uma.es
}

\section{Susana Rosa Navarro Rodríguez}

susanros@uma.es

Juan José Natera Rivas

jjnatera@uma.es

Departamento de Geografía

Universidad de Málaga (España)

\section{Resumen}

El objetivo de este trabajo es elaborar una propuesta para medir la diversidad del medio rural. Dada las limitaciones de los indicadores simples se recurre a la técnica del análisis multivariante. Como una primera experiencia el procedimiento propuesto se aplica en el espacio rural de la provincia de Málaga. La clasificación de los indicadores mediante componentes principales ha identificado tres factores como nuevas variables que explican la diversidad rural: "transformación productiva", buen status demográfico", "dinamismo local". A partir de este análisis se ha derivado 
dos tipologías, una estadística (análisis clúster) y otra directa que han permitido clasificar el territorio en ocho niveles de ruralidad. Concluyéndose que ambas tipologías describen acertadamente las diferencias básicas del medio rural en la provincia, por la relevancia y pertinencia de los mencionados factores.

Palabras claves: indicadores socioeconómicos; análisis factorial; ruralidad; clúster.

\begin{abstract}
The objective of this work is to elaborate a proposal to measure the diversity of the rural environment. Due to the limitations of simple indicators, the technique of multi-variant analysis is used. As a first experience, the proposed procedure is applied to the rural area of the province of Malaga. Indicator classification by main components has identified three factors as new variables that explain rural diversity: "productive transformation", "good demographic status " and " local dynamism ". Based on this analysis, two typologies have been derived: a statistical one (cluster analysis) and a direct one. Both of them have allowed to classify the territory into eight rurality levels. It is concluded that both typologies correctly describe the basic differences of the rural environment in the province, due to the relevance and appropriateness of the aforementioned factors.
\end{abstract}

Key words: socioeconomic indicators; factorial analysis; rurality; cluster.

\title{
1 Introducción: estado de la cuestión
}

El concepto de espacio rural ha ido cambiando considerablemente desde mediados del siglo XX, desde el momento en que las relaciones que se establecen entre el medio rural y el urbano se han ido haciendo más intensas, conformándose en la actualidad ambos espacios en una estrecha y dependiente imbricación. No obstante, la integración de lo rural en la sociedad global no resulta sencilla, ni homogénea, de forma que no en todos los espacios rurales la influencia de la ciudad se manifiesta con la misma intensidad, lo que nos lleva a plantear que en cada territorio la ruralidad se construye a partir de unas bases territoriales, culturales y productivas heterogéneas, lo que pone en evidencia que no existe una sola ruralidad (Dinis, 2006; Rye, 2006). Campo y ciudad, rural o urbano, no tienen el mismo significado en cualquier parte del mundo (García Ramón et al., 1995). En este sentido, en 1988, ya señalaba la Organización para la Cooperación y el Desarrollo Económico (OCDE) que "las estructuras sociales y económicas de las regiones rurales de la OCDE han cambiado considerablemente, al mismo tiempo que se alteraba su composición demográfica" (OCDE, 1988).

Al hilo de las transformaciones producidas en las áreas rurales, han proliferado los intentos y esfuerzos para definirlas y delimitarlas. La necesidad de marcar una frontera geográfica entre lo rural y lo urbano sigue siendo tan difícil como necesaria (Sancho Comíns \& Reinoso Moreno, 
2012). Además, esta necesidad se acrecienta si tenemos en cuenta que la puesta en práctica de las políticas de desarrollo rural exige delimitación precisa de estos espacios.

Desde el punto de vista académico, la concepción del mundo rural ha ido quedando paulatinamente obsoleta y, por tanto, evolucionando hacia otras a la par que la interdependencia entre lo rural y lo urbano se hacía más notoria. Se ha pasado desde una interpretación separada de los procesos desarrollados en el mundo rural frente al urbano, que se plasmaba en el enfoque dicotómico de los geógrafos, predominante hasta mediado del siglo XX (que implica una sociedad rural caracterizada por un alto peso de las tradiciones y costumbres), o la teoría del contraste de los sociólogos (que presenta el análisis de estos espacios como realidades contrapuestas y radicalmente enfrentadas entre sí), hasta la teoría aespacial desarrollada por Webber (1966) (en la que el dominio urbano no implica lugar, ni territorio, sino más bien grupos heterogéneos de personas que se comunican con otros en el espacio), pasando previamente por la del continuum rural-urbano de los sociólogos Soronkin y Zimmerman (1929) (en un intento de dar una explicación negando la existencia de una ruptura cualitativa apoyándose en la idea de un cambio gradual) y el modelo de la ciudad regional propuesto desde el campo de la geografía por Bauer y Roux (1976), que supone una interrelación entre el espacio rural y el urbano en aureolas de influencias decrecientes a partir de centros de irradiación, conformándose un espacio con mezcla de funciones heterogéneas (Larrubia Vargas, 1998).

La concepción de lo rural que ahora se plantea destaca la importancia de las actividades económicas rurales no agrícolas y su contribución a la generación de empleos e ingresos, así como las oportunidades de desarrollo que surgen de una mayor articulación entre lo urbano y lo rural. Y para ello es central la propuesta de concebir lo rural como territorio (Echeverri Perico \& Ribero, 2002).

En una revisión bibliográfica ${ }^{1}$ sobre los esfuerzos por establecer tipologías de espacios rurales los dos problemas más reiterativos que aparecen son, en primer lugar, los criterios a implementar para seleccionar los indicadores que definan a ambos espacios ya que, en muchas zonas, los tradicionalmente utilizados han venido perdiendo validez debido a las transformaciones en el medio rural y las nuevas articulaciones con lo urbano, concluyéndose que la tipología más apropiada es fuertemente contingente al tipo de problema que se pretende abordar $y$, en segundo lugar, la escala de análisis empleada (Reig Martínez et al., 2016), cuando la unidad administrativa que ha sido frecuentemente utilizada no está ajena de problemas e incongruencias.

1 El presente trabajo no pretende entrar en una consideración detallada de las múltiples facetas que caracterizan los espacios rurales, sobre lo que ya existe una amplia literatura especializada procedente de una variada gama de disciplinas científicas (ESPON, 2007), sólo esbozar los criterios y tipologías con más predicamento. 
Tradicionalmente y en esa concepción del medio rural por oposición de lo urbano se han venido usado indicadores simples (uno o combinación de varios) basados preferentemente en criterios cuantitativos, cualitativos o combinación de ambos. Respecto a los primeros, los más utilizados han sido el tamaño y la densidad de población, como se desprende de los análisis realizados por la ONU (1998) en base al tamaño demográfico y la OCDE (1994) en base a la densidad de población; criterios que también han sido ampliamente utilizados en la práctica de la estadística oficial, como la clasificación del INE en el caso de España, entre zonas urbanas, intermedias y rurales, en función de tres umbrales de población (INE, 2011). El problema de estos criterios es la disparidad de rangos existentes en su aplicación. En relación a las densidades poblacionales, éstas oscilan entre 100 y 500 habitantes $/ \mathrm{km}^{2}$ (Faiguenbaum, 2011), siendo un criterio muy sensible a la extensión territorial de la unidad administrativa local, además una distribución de tamaños muy heterogéneos puede generar resultados extraños en ambos extremos de la distribución (Rodríguez Pascual, 1997). En cuanto al número de habitantes también existe una gran disparidad al elegir cada Estado aplicar umbrales diferentes, aunque casi todos coinciden en los diez mil habitantes como el límite inferior urbano y los cinco mil como el límite superior rural (Faiguenbaum, 2011).

Para hacer frente a los problemas que generaba la utilización de estas variables, más recientemente la OCDE (Brezzi et al., 2011) ha llevado a cabo un nuevo intento clasificatorio, partiendo de los principios básicos de la antigua clasificación, incluye un nuevo criterio tipológico donde tiene en cuenta el carácter más o menos remoto de las áreas rurales, es decir, "el tiempo que necesita al menos el 50 \% de la población regional para acceder conduciendo un vehículo a la ciudad más cercana de más de 50000 habitantes" (Goerlich et al., 2016).

A la par que los criterios demográficos también han sido frecuente las delimitaciones del ámbito rural que han utilizado aspectos cualitativos (continuidad del espacio edificado, volumen de población agrícola, dotaciones e infraestructuras, etc.) o combinados con los cuantitativos. En este caso se suele combinar el volumen y densidad de población con indicadores específicos relativos al medio rural, entre los que cabe destacar la población activa agraria, aunque es una variable que pierde consistencia en relación directa con el descenso relativo de los activos agrarios en el mundo rural aunque en relación con el urbano las diferencias sigan siendo notables; el uso económico del territorio, referido a la intensidad de los usos por lo general más extensivos que en el espacio urbano, aunque no escapa de dificultad en la actualidad para establecer el grado de ocupación, ya que podemos encontrarnos con muchos espacios mixtos en zonas rurales, donde la coexistencia de usos extensivos e intensivos aportan mayor dificultad. Otros elementos que ocasionalmente se han utilizado han sido el número de mujeres que trabajan, el número de habitantes que reciben educación escolar, el grado de integración de entidades de población con otros de carácter superior, etc. Sin embargo, a estos últimos elementos no se les concede un valor decisivo para la diferenciación de la población, sino descriptivo y complementario. 
Dentro de esta tendencia hay que mencionar los diferentes intentos realizados por la entonces Comunidad Económica Europea (actual UE) para tipificar los municipios rurales. En 1988, la Comisión Europea, a través del documento de reflexión "El futuro del mundo rural", diferencia tres tipos de municipios en función de la intensidad del ruralismo (zonas rurales integradas, rurales y atrasadas). En 1995 este organismo vuelve a proponer una tipología basada en criterios cualitativos, diferenciando cuatro tipos de espacios rurales y, en 1997 la Dirección General VI de la Comunidad Europea propone la división en tres zonas, atendiendo a la densidad de población (densamente pobladas, intermedias y escasamente pobladas).

Como se aprecia, los criterios utilizados se basan fundamentalmente en una perspectiva dicotómica, en la que lo rural es concebido como residuo de lo urbano, basados en enfoques demográficos, en menor medida cualitativos, destacando bien sea la carencia de equipamiento e infraestructura típicamente urbana, o bien el predominio de actividades productivas primarias. Ello refleja la dificultad de abordar la complejidad de los territorios.

La insatisfacción con el uso de uno o dos únicos criterios en la clasificación de las zonas rurales (indicadores simples y su agregación subjetiva), al tiempo que las transformaciones acaecidas en el medio rural aumentaba la dificultad de seleccionar un número manejable de indicadores con los que poder operar, abrió camino a la práctica de métodos estadísticos más complejos obtenidos con técnicas de análisis factorial teniendo en cuenta muchas variables, incluyendo variables sociales como la renta familiar, el consumo, las prácticas sociales, culturales, religiosas, etc. Los análisis multivariantes resultan muy útil en estas circunstancias pues son capaces de generar síntesis de variables a partir de la comunalidad (la parte que comparten en su variabilidad) existente entre ellas.

Uno de los primeros indicadores complejos y quizás el más conocido es el índice de ruralidad de Cloke (1977) que combina 16 variables y elabora una clasificación en 5 grandes grupos que van desde las áreas más aisladas con descenso y envejecimiento de la población a los espacios residenciales periurbanos (Sancho Comíns \& Reinoso 2012).

A partir de Cloke, tanto desde el punto de vista académico como institucional han sido mucho los intentos de establecer tipologías del medio rural. A partir de la década de los 90 del siglo XX cabe destacar la clasificación de Clout (1993) que diferenció para las áreas rurales europeas tres grandes espacios: espacios rurales dinámicos con crecimiento económico, espacios rurales con bajos niveles de desarrollo económico, pero con un gran potencial de futuro, y aquellos espacios rurales en proceso de abandono con densidades de población muy bajas y con recursos ambientales poco aptos para la agricultura. Por su parte, Ballas et al. (2003), presentaron una tipología de áreas rurales europeas a nivel regional utilizando técnicas de análisis estadístico de clústeres con el objetivo de agrupar las regiones europeas y definir así varios tipos de áreas rurales. 
Halfacree (1995) intentó definir el medio rural a partir de representaciones sociales. Bibby y Shepherd (2004) distinguieron tres aspectos que pueden ser utilizados a la hora de delimitar las áreas urbanas y rurales: la superficie construida, el particular sistema de asentamientos y el papel de la "tierra" como fuente directa de ingresos y generación de riqueza. Waldorf (2006) diseñó un índice de ruralidad para los Estados Unidos partiendo de cuatro variables: tamaño demográfico, densidad de población, extensión del área urbana y lejanía o perificidad (Armas \& Macía, 2017).

En el contexto de la UE, Jornard et al (2009) realizan una tipología dentro de esta nueva orientación, en la que mantienen la densidad de población, pero le añaden dos criterios más: la accesibilidad y el tipo de cobertura del suelo (Reig Martínez et al, 2016). Posteriormente, en 2011, con la pretensión de suplir la influencia que tiene la extensión superficial del municipio a la hora de calcular la densidad de población, Eurostat (2012), junto con la DG-Regio (2011) y en colaboración con la OCDE (2012), acometió un proceso de revisión de las tipologías rural/urbano para que éstas sean consistentes entre sí a diversos niveles de agregación geográfica y que al mismo tiempo no dependan de los lindes administrativos, que era una de las cuestiones más problemáticas con la metodología inicial de la OCDE (1994; 2010) basada en densidades. La metodología parte de la disponibilidad de una grid de población con resolución de $1 \mathrm{~km}^{2}$ (Reig Martínez, 2016). Gracias a ello, actualmente la disponibilidad de una grid de población a nivel Europeo es una realidad. Los datos para España de dicha grid fueron elaborados por Goerlich y Cantarino (2012).

Siguiendo en el marco europeo y en el contexto del actual desarrollo rural, los Estados miembros deben aplicar una definición apropiada del medio rural y establecer una tipología de zona rural pertinente según el contexto, dada la diversidad de zonas rurales. Para definir las zonas rurales de cara a la aplicación de los Programas de Desarrollo Rural (PDR) los Estados miembros tienen la posibilidad de utilizar dos indicadores de base, por un lado, la definición de la OCDE de tres categorías diferentes de regiones (predominantemente rural, significativamente rural y predominantemente urbana) y, por otro lado, determinar la importancia de estas zonas en función de cuatro factores: porcentajes de territorio nacional, población, VAB y empleo ubicado en dichas zonas rurales.

A los Estados miembros se les permite adoptar su propia definición de rural, modificar la tipología de la OCDE o utilizar una definición alternativa como base. El resultado ha sido que ha prevalecido la modificación de la tipología de la OCDE y el uso de definiciones alternativas, no pudiéndose hablar de homogeneidad dentro de la UE en el enfoque de la definición. Por tanto, es imposible ignorar la variación existentes en los conceptos de ruralidad entre los Estados miembros. Dicha variación puede atribuirse a factores como la densidad de población, el tamaño de los municipios (diferentes entre países y regiones), lejanía y accesibilidad, zonas rurales y periurbanas, en los países en los que la emigración de las ciudades lleva a las personas a vivir en lugares que consideran aún rurales, la estructura de la ocupación del suelo, etc. 
En el ámbito de la investigación académica española, han sido variados los trabajos que mediante la técnica del análisis factorial de componentes principales tipifican los municipios rurales, bien a nivel nacional combinando tres (demografía, cobertura del suelo y accesibilidad de los municipios) (Goerlich et al., 2016) o 6 variables (demográficas, ocupación, habitabilidad, calidad de vida) (Ocaña \& Sánchez (2005); Prieto \& Ocaña (2010); o a nivel regional, como los trabajos de López González et al. (2004), López Ratón et al. (2005), Vázquez et al. (2008), Lois González (2014), etc., para Galicia; o el de Ocaña Ocaña (1993) y Márquez Fernández (2002) para Andalucía, o, por último el de Esparcia (2012) para la realidad valenciana a nivel municipal con el que diferenció dos grados de ruralidad.

En el ámbito privado han sido muchas las instituciones españolas que han elaborado informes en los que han desarrollado metodologías para tipificar los ámbitos rurales y urbanos. Uno de los más recientes es el de la Fundación BBVA (Reig Martínez et al., 2016) que propone una tipología que incorpora tres dimensiones: demografía, cobertura del suelo y accesibilidad. El Servicio de La Caixa (Camarero, 2009), a partir de tres grandes criterios de clasificación (estructura demográfica, desplazamientos de casa al trabajo y viceversa y porcentaje de residentes rurales de 30 a 49 años que en una década antes residían en un municipio diferente), ha generado una tipología en 5 tipo (desconexión, transición, local, líquido y denso). En 2015, el informe de la Fundación Encuentro (Franco, 2015), basándose en variables demográficas y económicas, estableció tres ámbitos rurales: la España rural litoral y periurbana, la rural interior competitiva y la rural no competitiva. Por su parte, la Fundación Foessa (Cáritas, 2015) toma como unidad de diagnóstico la comarca, siguiendo las utilizadas por el INE para realizar el censo agrario y, aplicando parámetros demográficos, físicos, distribución de núcleos poblacionales en el territorio, orientación productiva y estructura de la propiedad del espacio agrario, realiza una tipología de zonas rurales en 6 tipos (zonas de montaña, zonas de núcleos dispersos, zonas de llanuras cerealistas en minifundio, zonas de llanuras cerealistas en latifundio, zonas de dehesas y serranías en minifundios y zonas de dehesas y serranías en latifundio). Finalmente, cabe citar el estudio elaborado por IESA (2009) que, tomando como criterio la cohesión territorial, delimita tres grandes tipos de espacios: áreas con buen nivel de desarrollo basado en la agricultura, áreas del interior rural con importantes déficits estructurales y demográficos y áreas intermedias con una buena interacción rural/urbana (CESE, 2018).

Por último, y a efecto de las políticas públicas que se desarrollan no se puede soslayar la delimitación y clasificación de zonas rurales que se establece en los principales instrumentos para fomentar el desarrollo rural, como es la Ley de Desarrollo Sostenible del Medio Rural (LDSMR, 2007) que tomando en consideración factores como la densidad de población, la estructura económica y los niveles de renta establece tres tipos de áreas rurales que orienten a las Comunidades Autónomas a la delimitación y calificación de las zonas rurales definidas 
anteriormente en su respectivo territorio: zonas rurales a revitalizar, revitalizar, intermedias y periurbanas (Consejo para el Medio Rural, 2009).

En este punto y a modo de síntesis podemos apuntar que el tema de los indicadores viene constituyendo la clave de la cuestión, especialmente cuando la identificación del medio rural se ha hecho más dependiente del paisaje que de unas actividades/cultura específicas, y dentro del medio rural cabe descubrir una pluralidad de situaciones que no dependen únicamente de la organización agraria sino de distintos factores ligados a sus otras funciones, o a sus relaciones espaciales (renovadas funciones residenciales, nuevos equipamientos, ubicuidad de la actividad industrial, servicios, etc.). Al ampliarse el abanico de las variables potencialmente significativas, aumenta la dificultad de acertar al seleccionar un número manejable de indicadores con los que poder operar y, si la alternativa es la ampliación del número de variables, se acrecienta la incertidumbre sobre la agregación subjetiva de los indicadores simples propia de los análisis separativos. A pesar de estos problemas el interés de estos análisis no prescribe porque la diversidad rural persiste o se acrecienta.

Para superar la poca certeza de los indicadores simples y su agregación directa, se abre camino la práctica de otros métodos estadísticos más complejos (los métodos multivariantes). El recurso al análisis factorial resulta especialmente útil en esta finalidad de generar síntesis de variables a partir de la comunalidad (la parte que comparten en su variabilidad) existente entre ellas. De este modo, a partir de cualquier número de variables que se consideren expresivas de la diversidad rural, pueden obtenerse unos pocos factores (síntesis estadística de las variables) con los que identificar y describir esa potencial diversidad superando los dos problemas señalados: no hay limitación en la cantidad de variables, y su agrupación en factores comunes no es subjetiva sino estadística.

Este trabajo trata de ser una propuesta metodológica para medir la diversidad y complejidad actual del espacio rural, considerando nuevas dimensiones en relación a los cambios que se han venido sucediendo en los espacios rurales de las sociedades desarrolladas y utilizando técnicas de análisis multivariantes, adoptando como ámbito de comprobación los municipios rurales de la Provincia de Málaga.

\section{Planteamiento metodológico}

El objetivo señalado, identificar las variantes de cómo se manifiesta la diversidad del espacio rural en el nuevo contexto postindustrial, se desarrolla como una propuesta metodológica articulada en dos fases secuenciales, cada una de ellas basadas en métodos de análisis multivariante: la primera de ellas está orientada a identificar los ejes fundamentales de su diversidad, y la segunda, se centra en acotar las diferencias de las localidades con relación a dichos ejes, dentro de una tipología. 
La primera parte del trabajo tiene por tanto como finalidad la identificación de cuáles son los rasgos que subyacen como ejes fundamentales de la diferenciación de las localidades rurales, dentro del vasto conjunto de aspectos sociales y económicos susceptibles de consideración. La identificación de estos ejes es el aspecto clave de la investigación, que exige conocimiento de la realidad rural para seleccionar la información relevante, así como la elección de una herramienta para el análisis estadístico de las mismas. Al efecto se ha contado con la amplia aportación teórica de los estudios rurales, y el recurso metodológico del análisis factorial como herramienta estadística.

Los antecedentes sobre los análisis factoriales para explorar la diversidad rural se remontan, como se ha dicho, a los llamados índices de ruralidad. Aunque se diseñaran para describir mejor la realidad, generalmente con una finalidad aplicada, y en principio desligados de la teoría sociológica del contraste o de sus versiones más elaboradas como la del continuo rural-urbano, o el cambio social, tales índices se han basado habitualmente en una serie de variables significativas, tanto de los caracteres que identificaban la ruralidad en sentido tradicional "estricto" (rural profundo) como de los posibles cambios hacia una sociedad y economía más cercana a la de los medios urbanos.

En este modelo de análisis, constituye un reto la selección de las variables. Hay al menos tres exigencias que deben cumplir: en primer lugar, tener una relación potencial con los aspectos claves de la diversidad rural; en segundo lugar, mostrar una variabilidad espacial que identifique las diferencias entre las poblaciones objeto del análisis; en tercer lugar, deben de ofrecer entre ellas un grado de correlación suficiente para posibilitar su reducción a indicadores sintéticos mediante análisis factorial. Además de estas exigencias, hay que contar con un gran obstáculo estructural: las limitaciones de la información estadística desagregada a nivel de municipio.

La investigación ha contado con un trabajo previo de análisis muy general de las variables con desagregación municipal (demográficas, sociales, de actividad, de renta, de riqueza, de equipamientos etc.) a partir del banco de datos ICEA (Instituto de Cartografía y Estadística de Andalucía). El resultado de ese análisis previo mostró los límites de las variables utilizables a pesar de la amplitud de la información estadística hoy disponible. En general se desecharon todas aquellas que no mostraban correlaciones significativas con otras variables de carácter social o económico a nivel de municipio, puesto que la selección está orientada a un análisis factorial, y también con carácter general se excluyeron todas aquellas (algunas de indudable interés) con vacíos apreciables especialmente en los municipios de menor población por causa del secreto estadístico o errores de muestreo.

Dentro de las limitaciones existentes en las fuentes para el análisis municipal se han seleccionado un total de 21 variables por su significado en relación con algún criterio relacionado con las transformaciones de los espacios rurales (Tabla 1). 
Tabla 1. Variables seleccionadas

\begin{tabular}{|c|c|c|c|}
\hline Ejes temáticos & Indicadores & & Variables \\
\hline \multirow{3}{*}{ Dinamismo urbano } & \multirow{2}{*}{ Población } & 1 & Incremento relativo de la población en diez años (2016) \\
\hline & & 2 & Saldo migratorio. Tasa media (2012-2016) \\
\hline & Vivienda & 3 & Vivienda Secundaria/100 habitantes (censo de 2011) \\
\hline \multirow{3}{*}{$\begin{array}{c}\text { Modelo } \\
\text { demográfico }\end{array}$} & \multirow{2}{*}{ Tasas vitales } & 4 & Tasa de natalidad (2012-2016) \\
\hline & & 5 & Tasa de mortalidad (2012-2016) \\
\hline & Estructura de edad & 6 & Menores de 15 por 100 ancianos > 65 años (padrón 2017) \\
\hline \multirow[b]{2}{*}{ Evolución social } & \multirow[b]{2}{*}{ Estudios } & 7 & Sin estudios \% sobre mayores de 16 años (censo de 2011) \\
\hline & & 8 & $\begin{array}{l}\text { Con estudios universitarios, \% sobre mayores de } 16 \text { años } \\
\text { (censo de 2011) }\end{array}$ \\
\hline \multirow{5}{*}{$\begin{array}{l}\text { Mercado de } \\
\text { trabajo }\end{array}$} & Solidez & 9 & Asalariado fijo \% sobre total activos (censo de 2011) \\
\hline & \multirow{2}{*}{ Precariedad } & 10 & Asalariado eventual \% sobre total activos (censo de 2011) \\
\hline & & 11 & Trabajadores agrarios subsidiados por 100 habitantes \\
\hline & Déficit & 12 & Tasa media de paro (2016) \\
\hline & Movilidad & 13 & Afiliaciones locales/Afiliaciones de residentes (2016) \\
\hline \multirow{5}{*}{ Estructura actividad } & \multirow{2}{*}{ Por contratos } & 14 & \% Contratos Agricultura y Pesca (2016) \\
\hline & & 15 & \% Contratos en Servicios (2016) \\
\hline & \multirow{3}{*}{ Por ocupados } & 16 & \% Afiliados al R.G. de la Seguridad Social (2016) \\
\hline & & 17 & \% Afiliados al Régimen Especial Agrario (2016) \\
\hline & & 18 & Altas en actividades profesionales por 100 habitantes (2015) \\
\hline \multirow{2}{*}{$\begin{array}{l}\text { Ingresos sociales } \\
\text { (no productivos) }\end{array}$} & Pensionistas & 19 & Número de pensionistas por 100 habitantes (2016) \\
\hline & Pensiones & 20 & Pensión media (2016) \\
\hline Nivel de riqueza & Renta & 21 & Renta neta media declarada (2016) \\
\hline
\end{tabular}

Fuente: elaboración propia a partir del Censo Población (IECA, 2011)

y de las Estadísticas del MESS (Ministerio de Empleo y Seguridad Social, 2012-2017)

Es útil advertir que la selección de variables supone acotar la perspectiva desde la que se pretende analizar la diversidad del medio rural, y que la selección propuesta va orientada a detectar su grado de transformación social o económica, y no otros elementos de gran peso (relieve, sistema de poblamiento, usos del suelo, etc.) que son diferencias estructurales comunes en general a los 
municipios de los distintos ámbitos geográficos. Igualmente, se ha eludido como variable el volumen demográfico con la intención expresa de que la estructura de los asentamientos no condicione los resultados del análisis. Se ha valorado de más interés la comprobación de cómo se ajustan los factores obtenidos con las diferentes categorías de asentamientos, o con las diferencias que puedan reconocerse por ámbitos geográficos, como el marco en el que interpretar los resultados.

La segunda parte de la propuesta metodológica se refiere a la elaboración de una tipología de núcleos rurales a partir de los ejes de diferenciación obtenidos del análisis factorial, tomando tales factores como las nuevas variables. En esta finalidad, se abre un abanico de metodologías con larga tradición en la investigación geográfica, y se han desarrollado dos vías metodológicas diferentes: la clasificación directa y la estadística (en este caso aplicando el método del análisis clúster). Se ha efectuado este doble ejercicio porque además de la finalidad básica de obtener una clasificación razonada de los municipios analizados, se persigue mediante su comparación evaluar las fortalezas y limitaciones de cada uno de los dos acercamientos metodológicos.

El desarrollo de estos fundamentos metodológicos se aborda en los epígrafes correspondientes, pero antes de entrar en ellos es conveniente hacer una anotación sobre los caracteres de la Provincia de Málaga, el espacio que adopta el análisis como campo de experimentación.

El territorio de la Provincia de Málaga incluye ámbitos geográficos de diferente entidad, a los que se hará referencia con la denominación habitual de sus comarcas naturales, identificables salvo en el sector litoral con las demarcaciones tradicionales del Ministerio de Agricultura. Los contrastes entre ellas responden a la estructura física de la provincia que cabalga en la zona norte sobre el surco Intrabético (que asienta la Comarca de Antequera) y en su mayor extensión sobre la Penibética. A ella corresponden los espacios de montaña que forman las Comarcas de la Serranía de Ronda y Axarquía, y entre ambas la extensa hoya de Málaga, con la Comarca del Guadalhorce y el área urbana de la capital provincial. El tercer elemento con identidad propia es la banda litoral, territorialmente menos extenso, pero escenario junto a la capital provincial de grandes transformaciones urbanas desde mitad del siglo XX (Figura 1).

Se han seleccionado los municipios de menos de 20000 habitantes, como un límite operativo para delimitar los asentamientos rurales. Al establecer este umbral, el ámbito geográfico de estudio se ha retraído al interior de la provincia, de modo que el bajo Guadalhorce y la mayor parte del litoral por sus desarrollos urbanos han escapado a esta consideración de lo rural por el alto volumen de sus poblaciones. 
Figura 1. Localización geográfica del área de estudio. Provincia de Málaga
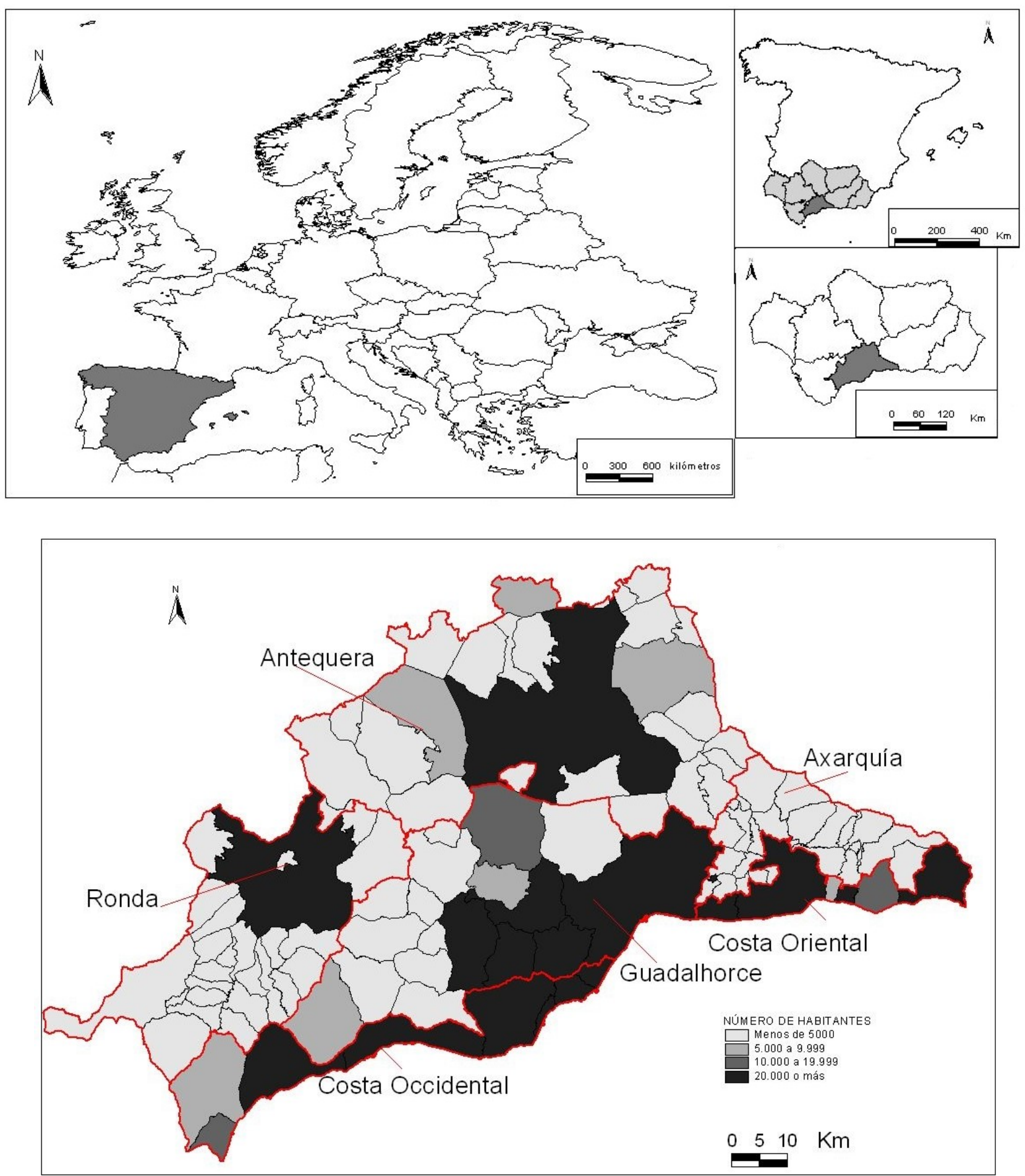

Fuente: elaboración propia a partir del Padrón de habitantes (Padrón de Habitantes, 2017)

Las tres comarcas interiores, Antequera, Ronda y Axarquía (salvo las cabeceras comarcales de las dos primeras) son las que se comprenden íntegramente bajo el umbral de población señalado. Del litoral oriental sólo dos municipios (Algarrobo y Torrox) mantienen poblaciones propias de los medios rurales. Y en la Costa Occidental, la más urbanizada, lo hacen cinco, asentados la mayoría en la montaña que forma el anfiteatro de la Costa del Sol. Por lo que respecta a la Comarca del 
Guadalhorce, el Bajo Guadalhorce se ha urbanizado como parte de la corona metropolitana, de modo que por debajo del umbral de 20000 habitantes hay en la comarca 12 municipios, pero todos ellos en la parte alta del valle, especialmente en su reborde montañoso.

Pocas localidades analizadas exceden los 5000 habitantes (11 de 84), característico de esta provincia donde la crisis histórica de la montaña y los desarrollos turísticos han ido transformando los que fueron grandes pueblos. De estas once localidades, seis corresponden a las comarcas litorales y todas son consecuencia de desarrollos de población reciente. Sólo cinco, que son municipios del interior (ninguno de ellos de montaña), se identifican con los grandes pueblos tradicionales. La montaña, por su parte, es responsable de la proliferación de poblaciones de menor tamaño: concentra todas las de menos de 500 habitantes (hay 16 en el análisis, la mayor parte localizadas en Ronda) y la gran mayoría de las de menos de 1000 (Tabla 2, Figura 1).

Tabla 2. Municipios de Málaga de < de 20000 habitantes por comarcas

\begin{tabular}{|l|c|c|c|c|c|c|c|c|}
\cline { 2 - 9 } & \multirow{2}{*}{} & Antequera & Ronda & Guadalhorce & Axarquía & $\begin{array}{c}\text { Costa } \\
\text { Occidental }\end{array}$ & $\begin{array}{c}\text { Costa } \\
\text { Oriental }\end{array}$ & \multicolumn{2}{|c|}{ Total } \\
\hline$<1000$ & 1 & 16 & 1 & 9 & 0 & 0 & 27 & $\begin{array}{c}32,7 \\
4\end{array}$ \\
\hline 1000 a 5000 & 16 & 6 & 9 & 13 & 2 & 0 & 46 & $\begin{array}{c}54,7 \\
6\end{array}$ \\
\hline $5000-10000$ & 4 & 0 & 1 & 0 & 2 & 1 & 8 & 9,52 \\
\hline$>10000$ & 0 & 0 & 1 & 0 & 1 & 1 & 3 & 3,57 \\
\hline Total & 21 & 22 & 12 & 22 & 5 & 2 & 84 & 100 \\
\hline Habitantes & 74599 & 20643 & 45675 & 33135 & 32620 & 21665 & 228337 & 100 \\
\hline
\end{tabular}

Fuente: elaboración propia a partir de IECA (2016)

Para contextualizar los resultados hay que tener presente dos circunstancias. Una es el momento temporal a que se refiere la información (2011-2017), un momento crítico de involución de los procesos de inmigración de la primera década de siglo, con signos de la crisis económica tan sensible en esta provincia tras la burbuja inmobiliaria. Por otra parte, queda fuera del universo seleccionado, no sólo las ciudades turísticas sino los municipios que ejemplificaban las transformaciones periurbanas del espacio rural. De modo que los mayores contrastes entre los pueblos que se reconocían hace un par de décadas y que venían producidos por estos factores, pueden que no sean tan relevantes en el momento actual por quedar pocos municipios en el ámbito costero o periurbano que no rebasen los 20000 habitantes. En consecuencia cabe esperar, salvo 
excepciones, un cuadro de contrastes más sutil y ligados a factores internos que los manifiestos varias décadas atrás en plena difusión urbana (Ocaña, 1993). ${ }^{2}$

\section{Los factores de diferenciación de los municipios rurales malagueños}

Metodológicamente se ha apostado por el análisis factorial ${ }^{3}$ para reducir la información de las 21 variables a unos factores comunes que se adoptarían, si su significado fuera clarificador, como los criterios objetivos para la diferenciación de los municipios rurales. El análisis factorial ha satisfecho las expectativas tanto como síntesis de la información, pues 4 factores resumen el 75,3\% de la varianza (Tabla 3), como por el significado de los factores obtenidos ${ }^{4}$.

Tabla 3. Autovalores y varianza (factores rotados)

\begin{tabular}{|c|c|c|c|}
\hline \multirow{2}{*}{ Factores } & \multirow{2}{*}{ Autovalores } & \multicolumn{2}{|c|}{ Varianza } \\
\cline { 3 - 4 } & & Propio (\%) & Acumulado (\%) \\
\hline 1 & 4.3 & 20.7 & 20.7 \\
\hline 2 & 4.0 & 19.0 & 39.6 \\
\hline 3 & 3.6 & 17.0 & 56.6 \\
\hline 4 & 3.1 & 14.7 & 71.3 \\
\hline
\end{tabular}

Fuente: elaboración propia a partir del Censo Población (IECA, 2011)

y de las Estadísticas del MESS (Ministerio de Empleo y Seguridad Social, 2012-2017)

A continuación se analizan los resultados, primeramente el significado de cada factor y posteriormente las puntuaciones en los municipios.

\subsection{Interpretación de los factores}

La interpretación de los factores se deduce del análisis de los coeficientes de la matriz de cargas (Tabla 4), basándola en el grupo de variables que tienen los coeficientes más elevados en cada uno de ellos.

2 Aquel ensayo tenía una atención importante sobre procesos ocurridos en las décadas precedentes, por la importancia de la intensa transformación de la red de asentamientos en la segunda mitad del siglo, de la que surgió la estructura actual de grandes núcleos litorales, o periurbanos, la desaparición de los grandes pueblos y los contrastes montaña y litoral y entorno periurbano. No se pretende volver sobre estos procesos, ya bien identificados. La intención es identificar la diversidad rural en la estructura territorial existente.

3 Sobre la aplicación del método de análisis factorial existe una variada referencia bibliográfica, algunas de las cuales aparecen recogidas al final del trabajo: Johsnton J.H. (1977), Anderson (1984), Uriel, \& Aldas (2005), Prieto \& Ocaña (2010).

4 El análisis se ha realizado dentro del programa SPSS, mediante el método de extracción de componentes principales, con rotación "varimax", seleccionando sólo los factores de valor superior a 1. 
De la matriz de carga se desprende que el factor 1 tiene coeficientes altos con las variables relacionadas con la estructura de actividad, sean empleados o contratos, y también aunque con coeficientes menores con otras tres variables: "pensión media" $(0,548)$, "renta neta media declarada" $(0,433)$ y "tasa media de paro" $(0,431)$. La asociación negativa de las variables de actividad agraria con las variables relacionadas a las actividades no agrarias y concretamente a los servicios justifica su identificación como "transformación productiva" en el sentido de menor dependencia agraria 5 . La relación positiva de otras variables ("pensión media" y "renta media declarada") aporta perfiles económicos positivos al sentido de este factor. Sin embargo, el signo positivo de la variable "tasa de desempleo", de menos interés por ser un coeficiente bajo, señala un matiz en la interpretación del factor que se hará patente en otras fases del análisis ${ }^{6}$ (Tabla 4).

Tabla 4. Comunalidad y matriz de cargas factoriales

\begin{tabular}{|l|c|c|c|c|c|}
\hline \multirow{2}{*}{ Variables } & \multirow{2}{*}{ Comunalidad } & \multicolumn{4}{c|}{ Cargas factoriales } \\
\cline { 5 - 7 } & & 1 & 2 & 3 & 4 \\
\hline $\begin{array}{l}\text { Incremento relativo de la población en diez } \\
\text { años (2016) }\end{array}$ & 0,878 & 0,27 & 0,38 & 0,80 & $-0,12$ \\
\hline Saldo migratorio. Tasa media (2012-2016) & 0,794 & 0,26 & 0,34 & 0,76 & $-0,16$ \\
\hline Vivienda secundaria (\%) & 0,81 & $-0,05$ & $-0,23$ & $-0,11$ & 0,86 \\
\hline Tasa de natalidad (2012-2016) & 0,654 & 0,03 & 0,80 & $-0,07$ & 0,01 \\
\hline Tasa de mortalidad (2012-2016) & 0,541 & $-0,04$ & $-0,69$ & $-0,25$ & 0,02 \\
\hline $\begin{array}{l}\text { (padrón 2017) } \\
\text { (panos por 100 habitantes >65 años }\end{array}$ & 0,842 & 0,05 & 0,90 & 0,13 & $-0,09$ \\
\hline Sin estudios (\%) (censo 2011) & 0,507 & $-0,20$ & $-0,52$ & $-0,40$ & 0,19 \\
\hline Con estudios universitarios (\%) (censo 2011) & 0,416 & 0,11 & 0,51 & 0,33 & $-0,20$ \\
\hline Asalariado fijo & 0,821 & 0,18 & 0,25 & 0,07 & $-0,85$ \\
\hline Asalariado eventual & 0,809 & $-0,08$ & 0,11 & $-0,23$ & 0,86 \\
\hline $\begin{array}{l}\text { Trabajadores agrarios subsidiados por 100 } \\
\text { habitantes }\end{array}$ & 0,703 & 0,43 & 0,05 & $-0,71$ & 0,08 \\
\hline
\end{tabular}

5 Las variables relativas a la actividad no se basan en los censos de población sino en las estadísticas del Ministerio de Empleo y Seguridad Social por lo que reflejan las localidades y no estrictamente a sus residentes.

6 El análisis posterior de las puntuaciones muestra que en municipios de poca población de la montaña (particularmente de Ronda) donde la actividad agraria ya no es significativa, el factor puntúa positivamente por esta retracción de la agricultura, frente a la pequeña presencia creciente o estable de la ocupación en servicios. Es el caso de Parauta, Jimera de Libar, Genalguacil o de Júzcar, municipios con poblaciones de 200 a 300 habitantes. El déficit del mercado de trabajo señala que la situación no es realmente de progreso. 
Tabla 4. Continuación

\begin{tabular}{|c|c|c|c|c|c|}
\hline \multirow{2}{*}{ Variables } & \multirow{2}{*}{ Comunalidad } & \multicolumn{4}{|c|}{ Cargas factoriales } \\
\hline & & 1 & 2 & 3 & 4 \\
\hline Tasa media de paro & 0,754 & $-0,78$ & $-0,09$ & $-0,06$ & 0,37 \\
\hline Afiliaciones locales/afiliaciones residentes & 0,728 & $-0,84$ & 0,11 & $-0,05$ & $-0,12$ \\
\hline \% Contratos agricultura y pesca & 0,655 & 0,77 & 0,12 & $-0,11$ & 0,17 \\
\hline \% Contratos en servicios & 0,741 & 0,75 & 0,20 & 0,21 & $-0,32$ \\
\hline \% Afiliados al R.G de la Seguridad Social & 0,896 & $-0,84$ & $-0,23$ & $-0,17$ & 0,33 \\
\hline \% Afiliados al Régimen Especial Agrario & 0,486 & 0,35 & 0,38 & 0,39 & $-0,26$ \\
\hline $\begin{array}{l}\text { Alta en actividades profesionales, por } 100 \\
\text { habitantes }\end{array}$ & 0,849 & 0,01 & 0,14 & 0,90 & $-0,11$ \\
\hline $\mathrm{N}^{\circ}$ de pensionistas, por 100 habitantes & 0,691 & $-0,36$ & $-0,59$ & $-0,39$ & 0,25 \\
\hline Pensión media & 0,572 & 0,55 & 0,41 & 0,10 & $-0,30$ \\
\hline Renta neta media declarada & 0,83 & 0,43 & 0,56 & 0,43 & $-0,38$ \\
\hline
\end{tabular}

Fuente: elaboración propia a partir del Censo Población (IECA, 2011)

y de las Estadísticas del MESS (Ministerio de Empleo y Seguridad Social, 2012-2017)

El factor 2 explica una proporción de la varianza casi similar al factor 1. Tiene coeficientes muy altos de las variables introducidas como indicadores del modelo demográfico y arrastra caracteres del modelo social como el nivel de estudios por su asociación con la estructura de edad, e igualmente con la variable "pensionistas" por su natural relación con el envejecimiento. La interpretación del factor está muy determinada por la variable "proporción de menores sobre ancianos" con un coeficiente de 0,902. Apoyado por la tasa de natalidad se identifica como un claro indicador de "buen estatus demográfico" que se corrobora con el coeficiente negativo de la tasa de mortalidad.

El factor 3 explica una varianza de $17 \%$ y está muy definido por cuatro variables. Tres con coeficientes altos positivos: "incremento de la población en la década anterior", "tasa media de crecimiento migratorio" y "ratio entre afiliados locales y afiliados residentes". El cuarto, alto y negativo, corresponde a la "tasa media de desempleo". La interpretación de este factor como "dinamismo local" estaría justificado por la variable crecimiento de población y el sentido de atracción que incorporan las variables "crecimiento migratorio" y "ratio entre afiliados por lugar de empleo y afiliados por lugar de residencia" $(0,904)$. Además, la variable "tasa de paro" detecta el menor déficit del mercado de trabajo, rasgo positivo que apoyan también otras variables con coeficientes menores. 
El factor 4 tiene un peso menor (14\% de la varianza) y está definido exclusivamente por las variables: "vivienda secundaria", "asalariados eventuales" y "asalariados fijos". Tal asociación identifica situaciones de "ocupación precaria y viviendas de ocupación temporal". Este factor no será tenido en cuenta para la posterior construcción de una tipología por varias razones: en parte por la ambigua interpretación de la variable vivienda secundaria cuando se analiza su distribución espacial $^{7}$ y, sobre todo, porque el factor viene forzado por la asociación negativa y constante de la variable trabajadores fijos con trabajadores eventuales, problema que no se advirtió como tal al seleccionar la información. Son razones para considerar este factor como un accidente derivado de una debilidad de la información introducida, con poco interés para el resto del análisis.

Reduciendo el análisis a los tres componentes primeros, aún se explica el 60 \% de la varianza introducida, y sigue siendo una excelente síntesis de la información. Los resultados también validan el procedimiento de selección de las variables en función de algunos criterios significativos como un buen proceso para encaminar los resultados. La confirmación es que se han resumido en tres nuevas variables cada una de ellas con un significado bien definido ("transformación productiva", "estatus demográfico-social" y "dinamismo local", respectivamente), que resultan muy útiles a la finalidad de este trabajo por la claridad de su interpretación en clave socioeconómica.

\subsection{Puntuación de los factores}

Cada factor es una variable nueva que igual que las iniciales presenta valores concretos en cada uno de los municipios. La medida se expresa en unidades de desviación estándar y el recorrido, como es propio de una distribución normal, excede en pocos casos los valores de 2 o -2 (Tabla 5).

El factor 1 muestra un cierto desequilibrio entre las puntuaciones positivas y negativas, siendo éstas más frecuentes. Pero lo más característico de su recorrido es la poca frecuencia de las puntuaciones positivas inferiores a 0,5 (Figura 2). Respecto al modelo territorial de la provincia, las puntuaciones del factor 1 no guardan una relación apreciables con el volumen de población de los municipios, aunque sí una clara diferencia entre los pocos de más de 10000 habitantes con el resto. Por el contrario, las diferencias entre las comarcas son más apreciables y ofrecen cierta perspectiva para reinterpretar, en el contexto actual, la apreciación del desarrollo de las comarcas habitualmente vinculado a sus potencialidades agrarias (Tabla 6).

7 La ambivalente significación de la vivienda secundaria, como segunda residencia de población foránea, o como la vivienda de los lugareños mantenida tras el abandono del lugar, abre el camino a dos interpretaciones de este mismo fenómeno: la de espacios en declive con excedente del parque de viviendas, o la de residencial turístico en espacios atrasados (la evolución de espacios rurales a meros parques temáticos). 
Tabla 5. Frecuencias de las puntuaciones de cada factor

\begin{tabular}{|c|c|c|c|}
\hline Puntuaciones $(\sigma)$ & Factor 1 & Factor 2 & Factor 3 \\
\hline 1 y más & 12 & 15 & 3 \\
\hline 0,5 a 1 & 19 & 11 & 14 \\
\hline 0,5 a 0 & 4 & 13 & 22 \\
\hline 0 a - - , 5 & 0 & 16 & 22 \\
\hline$-0,5$ a - 1 & 35 & 16 & 17 \\
\hline-1 y menos & 14 & 13 & 6 \\
\hline & 84 & 84 & 84 \\
\hline
\end{tabular}

Fuente: elaboración propia a partir del Censo Población (IECA, 2011) y de las Estadísticas del MESS (Ministerio de Empleo y Seguridad Social, 2012-2017)

Figura 2. Frecuencia de los valores del Factor 1



Fuente: elaboración propia a partir del Censo Población (IECA, 2011) y de las Estadísticas del MESS (Ministerio de Empleo y Seguridad Social, 2012-2017) 
Tabla 6. Distribución de frecuencias del Factor 1 por comarcas geográficas

\begin{tabular}{|c|c|c|c|c|c|c|c|c|}
\hline \multirow{2}{*}{ Comarcas } & \multirow{2}{*}{ Municipios } & \multicolumn{5}{|c|}{ Puntuaciones (intervalos de clases) } & \multicolumn{2}{|c|}{ Resumen } \\
\hline & & $=>1 \sigma$ & 0 a $1 \sigma$ & 0 a $-1 \sigma$ & $=<-1 \sigma$ & Total & Positivas & Negativas \\
\hline Antequera & 21 & 0,0 & 4,8 & 57,1 & 38,1 & 100 & 4,8 & 95,2 \\
\hline Ronda & 22 & 18,2 & 50,0 & 27,3 & 4,6 & 100 & 68,2 & 31,8 \\
\hline Guadalhorce & 12 & 16,7 & 41,7 & 41,7 & 0,0 & 100 & 58,3 & 41,7 \\
\hline Axarquía & 22 & 4,6 & 22,7 & 50,0 & 22,7 & 100 & 27,3 & 72,7 \\
\hline Costa Occidental & 5 & 80,0 & 20,0 & 0,0 & 0,0 & 100 & 100,0 & 0,0 \\
\hline Costa Oriental & 2 & 50,0 & 0,0 & 50,0 & 0,0 & 100 & 50,0 & 50,0 \\
\hline Todas & 84 & 14,3 & 27,4 & 41,7 & 16,7 & 100 & 35,0 & 49,0 \\
\hline
\end{tabular}

Fuente: elaboración propia a partir del Censo Población (IECA, 2011)

y de las Estadísticas del MESS (Ministerio de Empleo y Seguridad Social, 2012-2017)

Los valores del factor 2 presentan una frecuencia muy similar en cada clase, de modo que su curva sería plana, y los valores altos son tan frecuentes como los bajos. Al contrario que el factor 1, ofrece una correlación espacial apreciable con el volumen demográfico de los municipios y con los ámbitos geográficos, por lo que como nueva variable se ajusta muy bien a los contrastes geográficos básicos de la Provincia (Figura 4).

Figura 4. Frecuencias de las puntuaciones del Factor 2

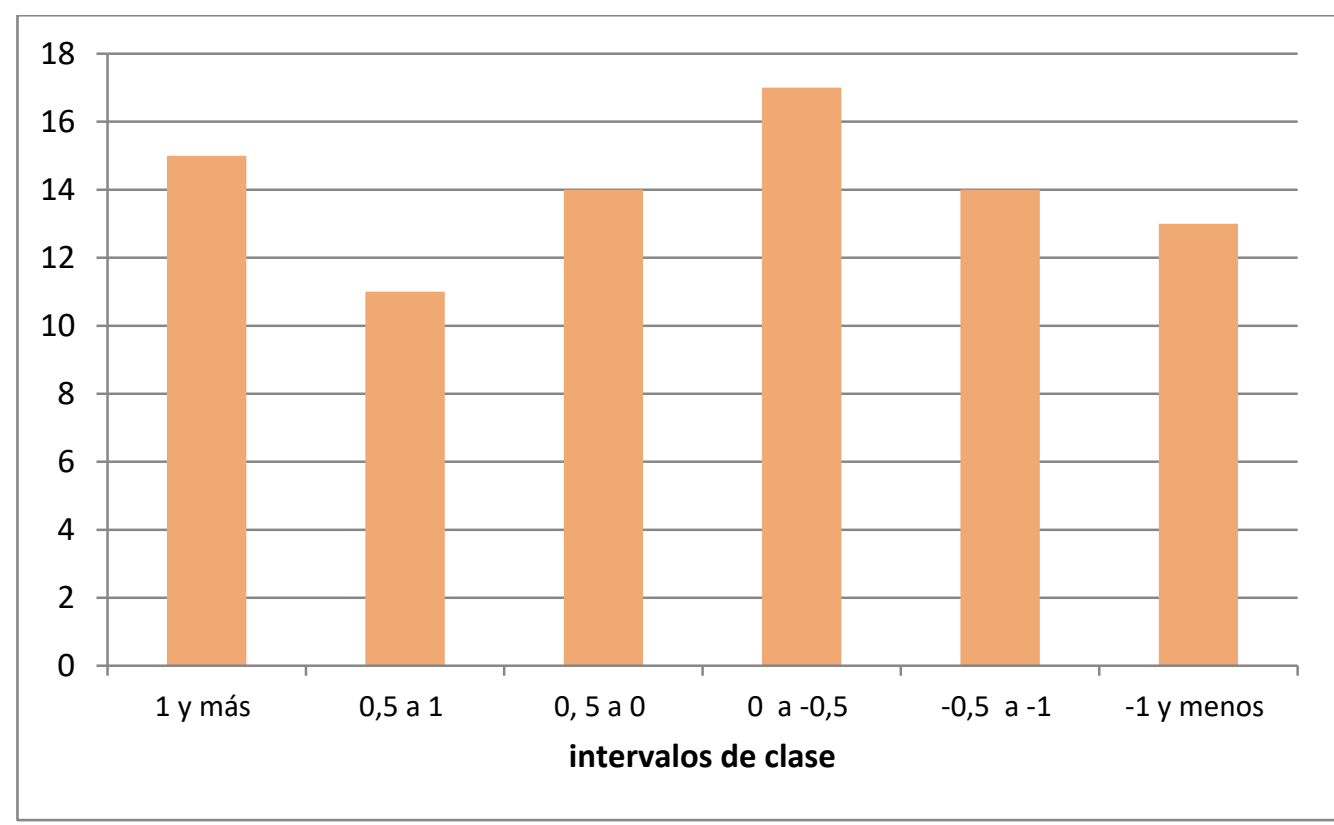

Fuente: elaboración propia a partir del Censo Población (IECA, 2011)

y de las Estadísticas del MESS (Ministerio de Empleo y Seguridad Social, 2012-2017) 
La correlación existente (coeficiente 0,65) entre las puntuaciones del factor 2 y el número de habitantes de cada municipio, en el análisis por intervalos de clases, se plasma en hechos significativos como la inexistencia en las poblaciones de menos de 1000 habitantes de puntuaciones positivas de este factor con connotación positiva en el estatus demográfico, o inversamente que en el rango de más de 5000 habitantes no se registren puntuaciones negativas (Tabla 7). También espacialmente las puntuaciones del factor 2 reflejan el contraste esencial en las trayectorias demográficas de los ámbitos naturales de esta provincia: el abandono histórico de la montaña se ve identificado en la proporción mucho más elevada de las puntuaciones negativas en las comarcas de Ronda y Axarquía, y la trayectoria de expansión demográfica del litoral, en la inexistencia de puntuaciones negativas del factor 2 (Tabla 8).

Tabla 7. Distribución de frecuencias del Factor 2 según población de los municipios

\begin{tabular}{|c|c|c|c|c|c|c|c|c|c|}
\hline \multirow{3}{*}{ Habitantes } & \multicolumn{8}{|c|}{ Intervalos de clases } & \multirow{3}{*}{$\begin{array}{c}\text { Total } \\
\%\end{array}$} \\
\hline & \multicolumn{2}{|c|}{$=>1 \sigma$} & \multicolumn{2}{|c|}{0 a $1 \sigma$} & \multicolumn{2}{|c|}{0 a $-1 \sigma$} & \multicolumn{2}{|c|}{$=<-1 \sigma$} & \\
\hline & $\%$ & $\mathrm{~N}^{\circ}$ & $\%$ & $N^{\circ}$ & $\%$ & $\mathrm{~N}^{\circ}$ & $\%$ & $\mathrm{~N}^{\circ}$ & \\
\hline$<1000$ & 7,4 & 2 & 3,7 & 1 & 51,9 & 14 & 37,0 & 10 & 100 \\
\hline $1000-5000$ & 13,0 & 6 & 43,5 & 20 & 37,0 & 17 & 6,5 & 3 & 100 \\
\hline 5000-10 000 & 75,0 & 6 & 25,0 & 2 & 0,0 & 0 & 0,0 & 0 & 100 \\
\hline$>10000$ & 33,3 & 1 & 66,7 & 2 & 0,0 & 0 & 0,0 & 0 & 100 \\
\hline Total & 17,9 & 15 & 29,8 & 25 & 36,9 & 31 & 15,5 & 13 & 100 \\
\hline
\end{tabular}

Fuente: elaboración propia a partir del Censo Población (IECA, 2011)

y de las Estadísticas del MESS (Ministerio de Empleo y Seguridad Social, 2012-2017)

Las puntuaciones del factor 3 que también apuntan como en las del factor 1 a ciertos aspectos de la situación socioeconómica, presentan contrastes menos definidos que aquel, y su asociación con los caracteres del modelo territorial, tan bien reproducidos por el factor 2, se hace en él más difusa, posiblemente por reflejar no tanto circunstancias estructurales, como el actual dinamismo de las localidades en un momento de alta inestabilidad.

Su gráfica de frecuencias es así muy acampanada (Figura 5), con un predominio importante de las puntuaciones centrales $(0,5$ a $-0,5)$, mientras que sólo el $11 \%$ de las observaciones tienen puntaciones igual o mayor de 1, predominando las negativas. Dentro de esta moderación de puntuaciones altas y positivas destaca una llamativa excepción: una puntuación de 7,02 que identifica la peculiaridad de un pequeño municipio de Sierra de las Nieves (Benahavís) en el área de irradiación turística de Marbella que ha eclosionado en la última década. 
Tabla 8. Distribución de frecuencias del Factor 2 por Comarcas geográficas

\begin{tabular}{|c|c|c|c|c|c|c|c|c|}
\hline \multirow{2}{*}{ Comarcas } & \multirow{2}{*}{ Municipios } & \multicolumn{5}{|c|}{ Intervalos de clases } & \multicolumn{2}{|c|}{ Resumen } \\
\hline & & $=>1 \sigma$ & 0 a $1 \sigma$ & 0 a $-1 \sigma$ & $=<-1 \sigma$ & total & Positivas & Negativas \\
\hline Antequera & 21 & 19,0 & 47,6 & 19,0 & 14,3 & 100 & 66,7 & 33,3 \\
\hline Ronda & 22 & 4,5 & 9,1 & 50,0 & 36,4 & 100 & 13,6 & 86,4 \\
\hline Guadalhorce & 12 & 16,7 & 50,0 & 33,3 & 0,0 & 100 & 66,7 & 33,3 \\
\hline Axarquía & 22 & 13,6 & 22,7 & 54,5 & 9,1 & 100 & 36,4 & 63,6 \\
\hline Costa Occidental & 5 & 80,0 & 20,0 & 0,0 & 0,0 & 100 & 100,0 & 0,0 \\
\hline Costa Oriental & 2 & 50,0 & 50,0 & 0,0 & 0,0 & 100 & 100,0 & 0,0 \\
\hline Todas & 84 & 17,9 & 29,8 & 36,9 & 15,5 & 100 & 47,6 & 52,4 \\
\hline
\end{tabular}

Fuente: elaboración propia a partir del Censo Población (IECA, 2011)

y de las Estadísticas del MESS (Ministerio de Empleo y Seguridad Social, 2012-2017)

Figura 5. Frecuencia de las puntuaciones del Factor 3

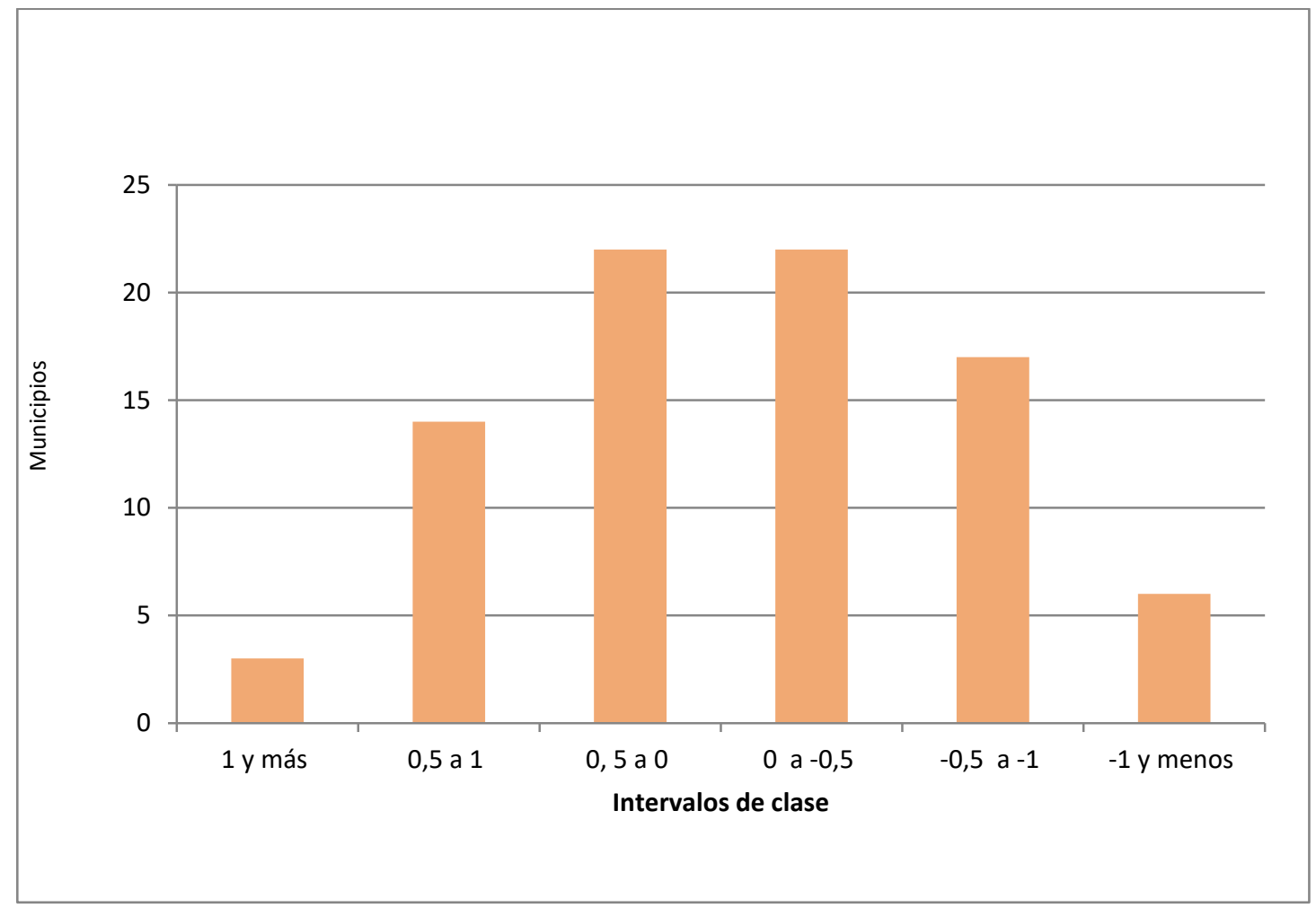

Fuente: elaboración propia a partir del Censo Población (IECA, 2011)

y de las Estadísticas del MESS (Ministerio de Empleo y Seguridad Social, 2012-2017) 
Vistas las puntuaciones en relación con el volumen demográfico de los municipios no se concluye que exista una asociación significativa aunque predominen las negativas en los más pequeños ${ }^{8}$. Por comarcas, sin embargo, las diferencias son más que notables en dos casos extremos, el de la comarca del Guadalhorce, donde todos los que mantienen el estatus rural puntúan negativamente, y en el extremo opuesto, las comarcas litorales, en que todos, salvo uno, puntúan positivamente. Las restantes no tienen un carácter uniforme en relación a este factor (Tabla 9).

Tabla 9. Distribución de frecuencias relativas del Factor 3 por comarcas geográficas

\begin{tabular}{|l|c|c|c|c|c|c|c|c|}
\hline \multirow{2}{*}{ Comarcas } & \multirow{2}{*}{ Municipios } & \multicolumn{5}{|c|}{ Intervalos de clase } & \multicolumn{2}{c|}{ Resumen frecuencias } \\
\cline { 3 - 9 } & & $=>1$ & 0 a 1 & 0 a -1 & $=<-1$ & total & Positivas & Negativas \\
\hline Antequera & 21 & 0,0 & 66,7 & 33,3 & 0,0 & 100 & 66,7 & 33,3 \\
\hline Ronda & 22 & 4,6 & 27,3 & 59,1 & 9,1 & 100 & 31,8 & 68,2 \\
\hline Guadalhorce & 12 & 0,0 & 0,0 & 75,0 & 25,0 & 100 & 0,0 & 100 \\
\hline Axarquía & 22 & 0,0 & 54,6 & 40,9 & 4,6 & 100 & 54,6 & 45,5 \\
\hline Costa Occidental & 5 & 40,0 & 40,0 & 20,0 & 0,0 & 100 & 80,0 & 20,0 \\
\hline Costa Oriental & 2 & 0,0 & 100 & 0,0 & 0,0 & 100 & 100 & 0,0 \\
\hline
\end{tabular}

Fuente: elaboración propia a partir del Censo Población (IECA, 2011)

y de las Estadísticas del MESS (Ministerio de Empleo y Seguridad Social, 2012-2017)

\section{Clasificación de los municipios en función de los factores de diferenciación del espacio rural malagueño}

En el proceso de constatar cuáles son los modelos de espacios rurales en este momento, el descubrimiento entre un conjunto significativo de variables de unos factores comunes ha sido un gran avance por sacar a la luz las claves por las que delimitar sus diferencias. De ahí la importancia de que las cargas factoriales hayan definido factores con significados claros en relación al objetivo propuesto. Así, de la batería de datos iniciales se desprende que esos modelos van a estar determinados por el diferente grado de transformación de la estructura productiva, por un estatus demográfico que varía de bueno a gravemente deteriorado y, por un dinamismo local que anima, o no, a las localidades.

A pesar de esta importante síntesis, el conjunto de municipios sigue mostrándose como la suma de singularidades también en lo referente a las puntuaciones de los factores. La comparación entre

8 También ocasionalmente puntúa positivamente en poblaciones muy pequeñas y en declive. El análisis de las variables demuestra que en tales casos se desvirtúa su significado, porque el paro o la atracción de ocupados refleja simples carencias locales: pocos activos y la residencia en otros municipios de algunos de sus ocupados. 
municipios deja intuir similitudes que pudieran reflejar los modelos que se están buscando, pero para darles forma es preciso reducir la singularidad de los casos a unos rangos o categorías generales, por lo que el paso siguiente es el de su clasificación.

Se reconoce la utilidad de las clasificaciones en el método científico, como proceso de generalización, al reducir a unas categorías generales la inmensa diversidad de los individuos observables en el mundo real. En el análisis geográfico hay una larga tradición en el uso de este recurso en la sistematización de la información y en la generación de modelos o tipologías. Su utilidad no es un tema discutido. Cabe plantear, sin embargo, el valor que tienen sus resultados. Una misma población con sus caracteres específicos puede encasillarse en diferentes conjuntos de clases, según los criterios de clasificación que se adopten. $Y$ es evidente que si no existe una solución única, deben sopesarse los criterios de clasificación y evaluar el significado de los resultados que se desprendan.

Partiendo de esta premisa se ha hecho un doble acercamiento al tema por dos vías metodológicas diferentes, la clasificación directa y la estadística siguiendo el método del análisis clúster. A continuación se presentan los resultados de cada una de las clasificaciones y se procede luego a su comparación. Este es un ejercicio que tiene como finalidad, más que la valoración de unas metodologías ampliamente aceptadas, comprobar si por debajo de las diferencias en sus respectivos resultados que se derivan de sus criterios metodológicos, existe una coincidencia de fondo que corrobore la existencia de unos modelos reales.

\subsection{Clasificación por método directo}

Una clasificación guiada deja la responsabilidad de los resultados en las decisiones que adopte el autor. El método directo tiene debilidades evidentes (no responder a una regla estadística sino a una apreciación subjetiva, o la necesidad de manejar la información en forma de intervalos) pero da la posibilidad de generar modelos definidos por el autor de acuerdo a determinados intervalos de las variables, generalmente claros y precisos para su interpretación posterior.

En el proceso de definir una tipología por el método directo hay que establecer un compromiso entre el número de intervalos en que se fragmente el recorrido de cada factor y el número de tipos que consecuentemente resulten de su combinación. Siendo tres las variables de la clasificación, se desprende que el número de tipos resulta poco operativo si no se simplifica el número de intervalos: con sólo dos intervalos (por ejemplo, positivos y negativos) se establecería 8 categoría (2x2x2), 27 de establecerse 3 intervalos $(3 \times 3 \times 3)$, o 64 si se diferenciaran $4(4 \times 4 \times 4)$. Teniendo presente el objetivo de generalización perseguido, la solución mejor será la que se resuelva en menor número de grupos, siempre que éstos sean claros. Se han realizado dos clasificaciones con solución en 18 y 8 tipos respectivamente, pues aunque la primera es poco operativa servirá de base para valorar los resultados de la segunda. 
La "Clasificación directa en 18 tipos" vino dictada del análisis previo del recorrido de los factores (Tabla 5) del que se concluyó que si bien el factor 1 podría simplificarse en solo dos intervalos, tal vez no fuera suficiente en el 2 y 3 . En efecto, las puntuaciones positivas del factor 1 en su mayoría por encima de 0,5 permiten diferenciar con bastante nitidez un amplio grupo de individuos que pueden calificarse como de estructura económica transformada, con clara diferencia respecto al resto con puntuaciones negativas de valores diferentes, que podría identificarse como no transformados o agrarios. La solución parece menos simple en los factores 2 y 3, por la alta frecuencia (especialmente en el factor 3) de las puntuaciones intermedias. Se establecieron tres intervalos para los factores 2 y 3 ; uno para las puntuaciones positivas superiores a 0,5, otro para los valores intermedios (entre 0,5 y $-0,5$ ) y un tercero para las puntuaciones negativas inferiores a 0,5 . Así, con dos clases en el factor 1; y tres clases (altas positivas, medias y altas negativas) en los factores 2 y 3 , se deriva una combinación de 18 clases (Tabla 10).

La aplicación de esta tipología permitió constatar la coherencia de los tipos con las peculiaridades geográficas locales que invita, si ese fuera el objetivo, a una descripción precisa de los matices a nivel de municipios en relación con sus peculiaridades naturales y las trayectorias precedentes. Se pudo concluir que de ella se deriva una buena disección de los resultados del análisis factorial, que por el contrario resulta poco eficiente para sintetizar las diferencias a un nivel general.

\section{Tabla 10. Criterios de la clasificación sistemática regular de 18 tipos}

\begin{tabular}{|c|c|c|c|c|c|c|c|c|}
\hline & & & \multicolumn{6}{|c|}{ Transformación Productiva } \\
\hline & & & \multicolumn{3}{|c|}{ Actividad transformada } & \multicolumn{3}{|c|}{ Actividad no transformada } \\
\hline & & & \multicolumn{3}{|c|}{ A } & \multicolumn{3}{|c|}{ B } \\
\hline & & & $\begin{array}{c}\text { Dinamismo } \\
\text { local alto }\end{array}$ & $\begin{array}{l}\text { Dinamismo } \\
\text { local } \\
\text { medio/bajo }\end{array}$ & $\begin{array}{l}\text { Dinamismo } \\
\text { local muy } \\
\text { bajo }\end{array}$ & $\begin{array}{l}\text { Dinamismo } \\
\text { local alto }\end{array}$ & $\begin{array}{c}\text { Dinamismo } \\
\text { local } \\
\text { medio/baj } \\
0\end{array}$ & $\begin{array}{l}\text { Dinamismo } \\
\text { local muy } \\
\text { bajo }\end{array}$ \\
\hline & & & A & B & C & $A$ & B & C \\
\hline \multirow{3}{*}{$\begin{array}{c}\text { Estatus } \\
\text { demográfico }\end{array}$} & Alto & 1 & Aa1 & Ab1 & Ac1 & $\mathrm{Ba} 1$ & $\mathrm{Bb} 1$ & $\mathrm{Bc} 1$ \\
\hline & $\begin{array}{c}\text { Medio/ } \\
\text { bajo }\end{array}$ & 2 & Aa2 & Ab2 & Ac2 & Ba2 & $\mathrm{Bb} 2$ & Bc2 \\
\hline & $\begin{array}{l}\text { Muy } \\
\text { bajo }\end{array}$ & 3 & Aa3 & Ab3 & Ac3 & Ba3 & Bb3 & $\mathrm{Bc3}$ \\
\hline
\end{tabular}

Fuente: elaboración propia a partir del Censo Población (IECA, 2011) y de las Estadísticas del MESS (Ministerio de Empleo y Seguridad Social, 2012-2017) 
La alternativa para superar esta dispersión de tipos es la reducción de todos los factores a solo dos intervalos: puntuaciones positivas y puntuaciones negativas. Las combinatorias posibles dan pie a la "clasificación en ocho categorías" (Tabla 11), que se presentan ordenadas de más a menos positivas, sobre el presupuesto de que los tres factores apuntan un carácter favorable y que la gradación puede establecerse desde un vértice con todas las puntuaciones positivas, al opuesto de todas ellas negativas (Tabla 12).

Tabla 11. Combinación de los signos positivos y negativos de los tres factores

\begin{tabular}{|c|c|c|c|c|}
\hline \multirow{2}{*}{ Tipos } & \multicolumn{2}{|c|}{$\begin{array}{r}\text { Estructura de actividad } \\
\text { transformada (+) }\end{array}$} & \multicolumn{2}{c|}{$\begin{array}{r}\text { Estructura de actividad no } \\
\text { transformada (-) }\end{array}$} \\
\cline { 2 - 5 } & $\begin{array}{c}\text { Dinamismo } \\
\text { local positivo } \\
(+)\end{array}$ & $\begin{array}{c}\text { Dinamismo local } \\
\text { negativo }(-)\end{array}$ & $\begin{array}{c}\text { Dinamismo } \\
\text { local positivo } \\
(+)\end{array}$ & $\begin{array}{c}\text { Dinamismo local } \\
\text { negativo (-) }\end{array}$ \\
\hline $\begin{array}{l}\text { Estatus demográfico } \\
\text { Positivo (+) }\end{array}$ & +++ & +-+ & -++ & --+ \\
\hline $\begin{array}{l}\text { Estatus demográfico } \\
\text { Negativo (-) }\end{array}$ & ++- & +- & -+- & -- \\
\hline
\end{tabular}

Fuente: elaboración propia

Tabla 12. Resultados de la clasificación directa en ocho tipos

\begin{tabular}{|c|c|c|c|c|}
\hline \multicolumn{2}{|c|}{ Tipos } & Municipios & Habitantes \\
\hline F1-F3-F2 & $N^{\circ}$ & 1 & $\begin{array}{r}\text { Con estructura de actividad transformada, } \\
\text { dinamismo local positivo y buen estatus } \\
\text { demográfico negativo }\end{array}$ & 69634 \\
\hline-++ & 2 & $\begin{array}{r}\text { Con estructura de actividad no transformada, } \\
\text { dinamismo local positivo y buen estatus } \\
\text { demográfico }\end{array}$ & 11 & 38163 \\
\hline+-+ & 3 & $\begin{array}{r}\text { Con estructura de actividad transformada, sin } \\
\text { dinamismo local positivo y buen estatus } \\
\text { demográfico }\end{array}$ & 11 & 46659 \\
\hline++- & 4 & $\begin{array}{r}\text { Con estructura de actividad transformada, } \\
\text { dinamismo local positivo y estatus demográfico } \\
\text { negativo }\end{array}$ & 8 & 20286 \\
\hline-+ & 5 & $\begin{array}{r}\text { Con estructura de actividad no transformada, } \\
\text { dinamismo local negativo y buen estatus } \\
\text { demográfico }\end{array}$ & 12 & 40660 \\
\hline-+ & 6 & $\begin{array}{r}\text { Con estructura de actividad no transformada, } \\
\text { dinamismo local positivo y estatus demográfico } \\
\text { negativo }\end{array}$ & 14 & 2785 \\
\hline
\end{tabular}


Tabla 12. Continuación

\begin{tabular}{|c|c|c|c|c|}
\hline \multicolumn{2}{|c|}{ Tipos } & \multirow{2}{*}{ Descripción } & \multirow{2}{*}{ Municipios } & \multirow{2}{*}{ Habitantes } \\
\hline F1-F3-F2 & $N^{\circ}$ & & & \\
\hline+-- & 7 & $\begin{array}{c}\text { Con estructura de actividad transformada, } \\
\text { dinamismo local negativo y estatus demográfico } \\
\text { negativo }\end{array}$ & 9 & 7653 \\
\hline$\cdots$ & 8 & $\begin{array}{c}\text { Con estructura de actividad no transformada, } \\
\text { dinamismo local negativo y estatus demográfico } \\
\text { negativo }\end{array}$ & 13 & 15493 \\
\hline
\end{tabular}

Fuente: elaboración propia a partir del Censo Población (IECA, 2011)

y de las Estadísticas del MESS (Ministerio de Empleo y Seguridad Social, 2012-2017)

Cada clase tiene un peso muy parecido en cuanto al número de municipios que engloba (la mediana de las puntuaciones es muy próxima a 0). Muestran, sin embargo, mayor desigualdad en el volumen de población que representan (Tabla 12), lo que parece apuntar algún tipo de relación con el volumen demográfico de los municipios. De sus análisis se desprende que el tamaño de los municipios no determina su adscripción a una u otra clase, pero es significativa tanto la inexistencia de municipios de menos de 1000 habitantes en los grupos que se han ordenado en los primeros puestos, como la inexistencia en las clases más bajas de los mayores de 5000.

De la tipología resultante, sólo dos tipos suman positivo dinamismo local y positivo estatus demográfico. Parecieran los mejores situados en el ranking, si bien difieren en tener, o no, una estructura de actividad transformada. El tipo 1, con estructura de actividad transformada, es el que reúne la condición de ser el menos numeroso, pero con mayor población. Engloba poblaciones grandes, en su totalidad en el entorno del litoral. El tipo 2, con dinamismo y sin envejecimiento pero con estructura de actividad no transformada, tiene su asiento en los pueblos "agrarios" de Antequera, además de un término (Algarrobo) de la Costa Oriental.

Dos tipos suman estatus demográfico negativo y dinamismo local negativo. Ocuparían los últimos puestos de ese mismo ranking. Uno de ellos (el 8) que añade estructura de actividad no transformada, identifica a pueblos tradicionales en crisis, y tiene cierta dispersión en la provincia, pero es en la comarca de Ronda donde tiene más presencia. Esta concentración es absoluta en el grupo 7 que merece considerarse el más desfavorable de todos ${ }^{9}$, que se forma únicamente a base de pequeñas poblaciones apenas productivas de dicha comarca. Entre ambos bloque, quedan cuatro grupos que sólo tienen valor positivo bien en dinamismo local o bien en estatus

9 La puntuación positiva del factor 1 es de dudosa interpretación como un carácter favorable cuando se combina con puntuaciones negativas en los restantes. 
demográfico. Alternancia que coincide tanto con estructuras de actividad transformada (grupos 3 y 4) o no transformadas (grupos 5 y 6). De estos, dos de ellos, el 3 y el 5, agrupan gran población. El 3 identifica pueblos más bien grandes con estructura de actividad transformada y buen estatus demográfico aunque sin dinamismo, es especialmente significado en la comarca del Guadalhorce. El tipo 5, de estructura de actividad no transformada, dinamismo local negativo y buen estatus demográfico, identifica pueblos agrarios estables, de las comarcas de Antequera, Guadalhorce e incluso de la Axarquía.

Tabla 13. Proporción por comarcas de municipios clasificados en cada tipo de la clasificación directa

\begin{tabular}{|c|c|c|c|c|c|c|c|c|}
\hline $\begin{array}{l}\text { Tipos/ } \\
\text { Números } \\
\text { (F1-F3-F2) }\end{array}$ & Descripción & $\frac{\substack{\frac{0}{0} \\
\frac{0}{2}}}{\frac{d}{2}}$ & $\begin{array}{l}\frac{\pi}{0} \\
\frac{0}{0} \\
\alpha\end{array}$ & $\begin{array}{l}0 \\
0 \\
0 \\
\frac{0}{\pi} \\
\frac{\pi}{0} \\
\frac{\pi}{0} \\
0\end{array}$ & 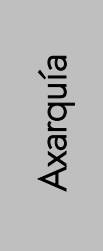 & 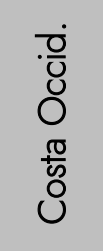 & 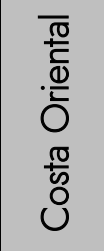 & $\frac{\frac{\pi}{0}}{\frac{c}{2}}$ \\
\hline $\begin{array}{c}1 \\
(+++)\end{array}$ & $\begin{array}{c}\text { Con estructura de actividad transformada, } \\
\text { dinamismo local positivo y buen estatus } \\
\text { demográfico negativo }\end{array}$ & 0,0 & 0,0 & 0,0 & 4,6 & 80,0 & 50,0 & 7,1 \\
\hline $\begin{array}{c}2 \\
(-++)\end{array}$ & $\begin{array}{c}\text { Con estructura de actividad no transformada, } \\
\text { dinamismo local positivo y buen estatus } \\
\text { demográfico }\end{array}$ & 38,1 & 4,6 & 0,0 & 4,6 & 0,0 & 50,0 & 13,1 \\
\hline $\begin{array}{c}3 \\
(+-+)\end{array}$ & $\begin{array}{c}\text { Con estructura de actividad transformada, sin } \\
\text { dinamismo local positivo y buen estatus } \\
\text { demográfico }\end{array}$ & 4,8 & 9,1 & 50,0 & 4,6 & 20,0 & 0,0 & 13,1 \\
\hline $\begin{array}{c}4 \\
(++-)\end{array}$ & $\begin{array}{c}\text { Con estructura de actividad transformada, } \\
\text { dinamismo local positivo y estatus } \\
\text { demográfico negativo }\end{array}$ & 0,0 & 22,7 & 0,0 & 18,2 & 0,0 & 0,0 & 10,7 \\
\hline $\begin{array}{c}5 \\
(--+)\end{array}$ & $\begin{array}{c}\text { Con estructura de actividad no transformada, } \\
\text { dinamismo local negativo y buen estatus } \\
\text { demográfico }\end{array}$ & 23,8 & 0,0 & 16,7 & 22,7 & 0,0 & 0,0 & 14,3 \\
\hline $\begin{array}{c}6 \\
(-+-)\end{array}$ & $\begin{array}{c}\text { Con estructura de actividad no transformada, } \\
\text { dinamismo local positivo y estatus } \\
\text { demográfico negativo }\end{array}$ & 28,6 & 4,6 & 0,0 & 27,3 & 0,0 & 0,0 & 15,5 \\
\hline $\begin{array}{c}7 \\
(+--)\end{array}$ & $\begin{array}{c}\text { Con estructura de actividad transformada, } \\
\text { dinamismo local negativo y estatus } \\
\text { demográfico negativo }\end{array}$ & 0,0 & 36,4 & 8,3 & 0,0 & 0,0 & 0,0 & 10,7 \\
\hline $\begin{array}{c}8 \\
(---)\end{array}$ & $\begin{array}{c}\text { Con estructura de actividad no transformada, } \\
\text { dinamismo local negativo y estatus } \\
\text { demográfico negativo }\end{array}$ & 4,8 & 22,7 & 25,0 & 18,2 & 0,0 & 0,0 & 15,5 \\
\hline & & 100 & 100 & 100 & 100 & 100 & 100 & 100 \\
\hline
\end{tabular}

Fuente: elaboración propia a partir del Censo Población (IECA, 2011) 
y de las Estadísticas del MESS (Ministerio de Empleo y Seguridad Social, 2012-2017)

Al describir los tipos se ha ido apuntando vinculaciones, a veces muy exclusivas, con algunas comarcas naturales de modo que su distribución sobre la provincia dista mucho de ser aleatoria y sugiere, por el contrario, relaciones de gran interés con las particularidades geográficas de las comarcas (Tabla 13).

Subrayando esa apreciación, se advierte que salvo la comarca de la Axarquía, más distribuida entre diversos tipos, en las restantes comarcas la identificación con algunos tipos concretos es importante. La más definida es la del Guadalhorce, con un $50 \%$ de sus términos clasificados en el tipo 3, propio de pueblos transformados sin envejecimiento y sin dinamismo. La comarca de Antequera, aunque se desdibuje en varios tipos, es también muy precisa en torno a los modelos de no transformación de la actividad productiva y buen estatus demográfico: con un $38 \%$ de sus municipios en el grupo 2 que incluye dinamismo local, y un $23 \%$ en el tipo 5 que no lo incluye. También es muy definido el perfil de la comarca de Ronda, en su caso como ya se apuntó en los dos tipos peores, el 7 y el 8 que suman casi el $60 \%$ de sus municipios. Y por supuesto el espacio litoral, el occidental con el $80 \%$ en el grupo 1, el más positivo, y entre el 1 y el 2, el sector oriental.

Resultan también de interés los municipios que no se ajustan a los tipos de la clasificación que son dominantes en sus comarcas, la razón de sus peculiaridades se debe, en la mayoría de los casos, a que las comarcas no son uniformes en sus rasgos geográficos fundamentales. En este sentido, destaca en Antequera un grupo de municipios que rompen con las pautas de buen estatus demográfico de sus modelos, y se clasifican en el tipo 6 (Alfarnate, Alfarnatejo, Cuevas de San Marcos, Riogordo, Villanueva de Algaidas, Villanueva de Tapia y Cañete la Real), todos ellos se emplazan en los bordes de la depresión de Antequera, lo que les hace más afines en muchos rasgos a las montañas vecinas. También se justifica por esa misma circunstancia la presencia del grupo 8 en algunos municipios de la comarca del Guadalhorce (es el caso de Guaro, Carratraca, Tolox que son de marcado carácter serrano). En el caso de la comarca de Ronda, tan identificada por los grupos 7 y 8 , los municipios de la depresión que no forman parte de la Serranía, aparecen clasificados en los grupos 2 (El Burgo, situado en la Sierra de las Nieves) y 3 (Arriate, en el llano de Ronda). La Serranía es por el contrario muy uniforme. Escapa a los modelos más negativos sólo uno de sus términos, Cortes de la Frontera (grupo 3) que además es el único núcleo de más de 4000 habitantes, pero la anomalía más numerosa es la de seis municipios clasificados en el grupo 6, que discrepa del modelo general por dinamismo local positivo, es un mero espejismos ligado a la distorsión que introducen las localidades de muy poca población (todos ellos en torno a los 200 habitantes) en el factor 3.

La conclusión es que los tipos de esta clasificación simplificada describen muy bien el espacio provincial. Se ha realizado la comparación con la más detallada de 18 tipos con la conclusión de 
que a pesar de su menor definición se puede adoptar sin reparos. A la ventaja de su operatividad, le acompaña una definición muy clara de los tipos, cuya validez queda reafirmada por la coherencia que presenta con los rasgos geográficos de los distintos ámbitos de la provincia.

\subsection{Clasificación por el método de análisis clúster}

Al análisis clúster se le reconoce mayor objetividad que a las clasificaciones directas, aunque es un método muy flexible y por tanto susceptible de producir resultados diferentes según las decisiones del autor. En el objetivo de este análisis se valora una propiedad específica del método: que detecte los agrupamientos por la posición de los casos en el espacio n-dimensional de las variables, es decir, grupos "naturales" en función de los factores.

Siendo éste el objetivo primordial se ha optado entre las técnicas de clusterización, por el modelo nuclear, que parte de establecer unos centros de acuerdo a la posición de los casos en ese espacio de n-dimensiones que son el origen de los conglomerados, a los que luego, según reglas establecidas y sucesivas reiteraciones se asignan todos los casos optimizando su agrupamiento.

El método no determina el número de grupos, por lo que se recurre normalmente a reproducir la clasificación con soluciones múltiples (con diferente número de grupos) y se comparan los resultados. Tras comparar varia soluciones, se ha optado por la clasificación en 8 conglomerados, porque da resultados claros y por similitud en número de tipos a la clasificación directa.

Tabla 14. Número de casos y valores medios de los factores en cada conglomerado

\begin{tabular}{|c|c|c|c|c|}
\hline \multirow{2}{*}{$\begin{array}{c}\text { Clústeres, } \\
\text { de menor a } \\
\text { mayor }\end{array}$} & \multirow{2}{*}{ Casos } & \multicolumn{3}{|c|}{ Puntuación media } \\
\cline { 3 - 5 } & 1 & 1,41 & 7,02 & 1,15 \\
\hline 1 & Factor 1 & Factor 3 & Factor 2 \\
\hline 2 & 6 & 1,36 & 0,48 & 1,2 \\
\hline 3 & 7 & 1,48 & $-0,62$ & $-0,39$ \\
\hline 4 & 11 & 0,65 & $-0,82$ & 0,97 \\
\hline 5 & 12 & 0,54 & 0,37 & $-1,39$ \\
\hline 6 & 13 & $-1,07$ & 0,37 & $-0,77$ \\
\hline 7 & 14 & $-1,07$ & 0,12 & 0,9 \\
\hline 8 & 20 & $-0,24$ & $-0,37$ & $-0,11$ \\
\hline
\end{tabular}

Fuente: elaboración propia a partir del Censo Población (IECA, 2011)

y de las Estadísticas del MESS (Ministerio de Empleo y Seguridad Social, 2012-2017) 
Los conglomerados obtenidos son desiguales en tamaño, oscilan desde un solo individuo (clúster 1) hasta un máximo de 20 (clúster 8). Las características de cada conglomerado se desprenden del valor medio de sus individuos respecto a los factores (Tabla 14). Aunque la numeración es en función de su tamaño, para el análisis se les ha ordenado en una jerarquía en razón de sus significados más a menos positivos, sobre el mismo presupuesto ya aplicado de que cada factor es un carácter favorable (Tabla 15).

Tabla 15. Interpretación de los clústeres (de situación más positiva a menos positiva)

\begin{tabular}{|c|c|c|}
\hline $\begin{array}{c}\text { Número } \\
\text { (por } \\
\text { tamaño) }\end{array}$ & $\begin{array}{c}\text { Orden } \\
\text { de mejor a } \\
\text { peor }\end{array}$ & Descripción \\
\hline 1 & A & $\begin{array}{r}\text { Estructura de actividad transformada, } \\
\text { con muy buen estatus demográfico y muy dinámicos }\end{array}$ \\
\hline 2 & B & $\begin{array}{r}\text { Estructura de actividad transformada, } \\
\text { con buen estatus demográfico y dinámicos }\end{array}$ \\
\hline 4 & C & $\begin{array}{r}\text { Estructura de actividad transformada } \\
\text { con buen estatus demográfico sin dinamismo }\end{array}$ \\
\hline 7 & E & $\begin{array}{r}\text { Estructura de actividad no transformada } \\
\text { y buen estatus demográfico. }\end{array}$ \\
\hline 6 & F bajo (-) en estructura de actividad transformada, \\
en dinamismo y en estatus demográfico.
\end{tabular}

Fuente: elaboración propia a partir del Censo Población (IECA, 2011)

y de las Estadísticas del MESS (Ministerio de Empleo y Seguridad Social, 2012-2017)

La frecuencia de la distribución de los municipios en los clústeres cobra una mayor claridad cuando éstos se ordenan en esta gradación según sus significados (Figura 5). En la posición central de esta gradación se sitúa el Clúster 8 (el más numeroso) que identifica el modelo intermedio de los municipios. En los extremos de una curva muy regular, los clústeres 1 y 2 que en realidad pueden identificarse en uno sólo como se ha dicho, dan la versión más positiva de las tres variables con siete municipios en ella. Y en el extremo opuesto, el clúster 3 con otros siete municipios ofrece la versión menos positiva respecto al conjunto de estas tres variables. También se aprecia una 
distribución muy clara así ordenados si se quiere observar la relación de los clúster con el tamaño de los municipios (Figura 6). Se ha presentado gráficamente en sus frecuencias absolutas. Todos los municipios de más de 5000 habitantes se distribuyen en los clúster de la izquierda, la parte positiva. Todos los clústeres restantes incluido el más numeroso central, están formados por municipios de menos de 5000 (en realidad son la gran mayoría).

Figura 5. Municipios en cada clúster

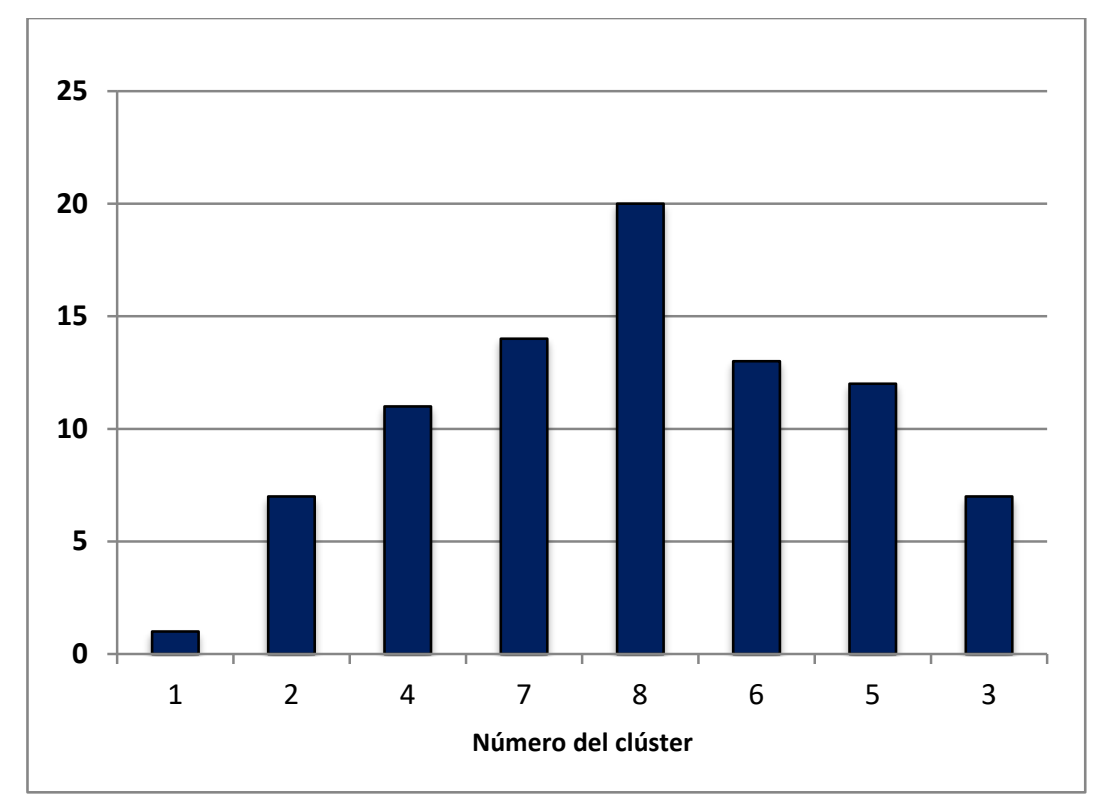

Fuente: elaboración propia a partir del Censo Población (IECA, 2011) y de las Estadísticas del MESS (Ministerio de Empleo y Seguridad Social, 2012-2017)

Figura 6. Frecuencia relativa de los clústeres según tamaño de los municipios

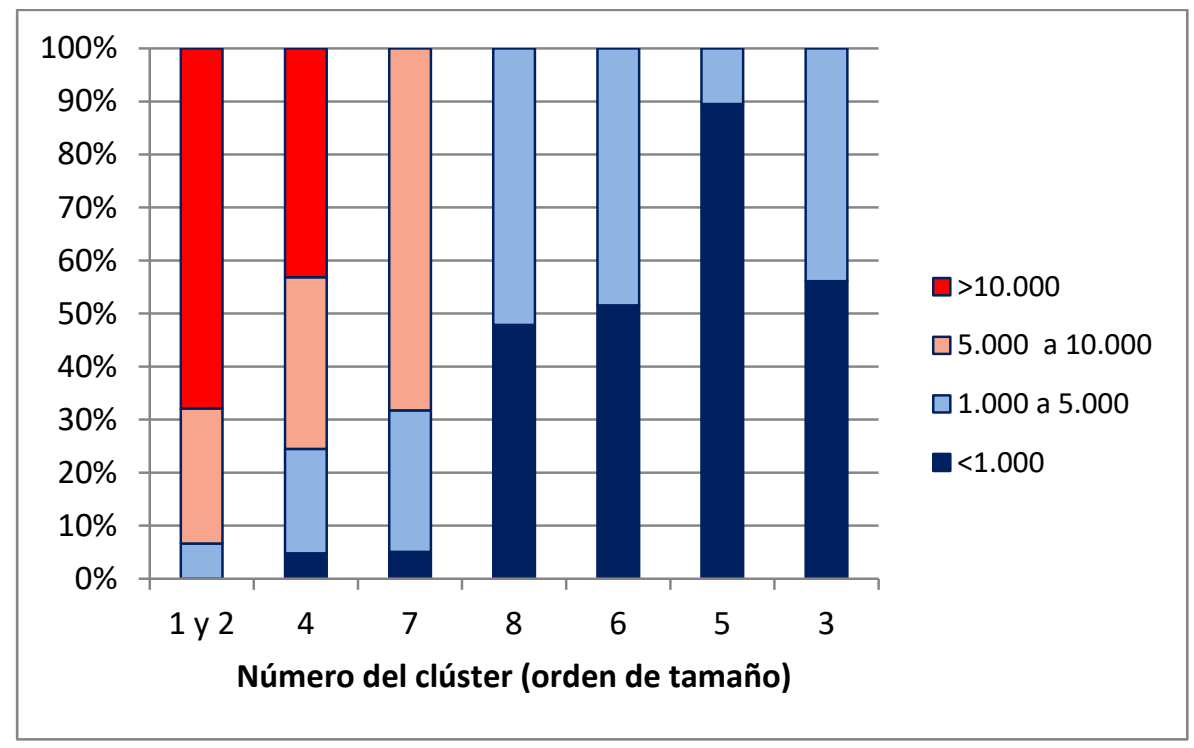

Fuente: elaboración propia a partir del Censo Población (IECA, 2011) y de las Estadísticas del MESS (Ministerio de Empleo y Seguridad Social, 2012-2017) 
Por último, la manera en que los clústeres se descomponen entre las comarcas refuerza la idea del buen resultado de la clasificación (Tabla 16). Pueden subrayarse algunos trazos destacados de esta distribución en relación con los caracteres de los ámbitos comarcales:

a) En primer lugar, cómo la comarca de la Costa Occidental se engloba en su totalidad en los clúster 1 y 2 ("estructura de actividad muy transformada, con buen estatus demográfico y dinámicos"). No es preciso justificar nuevamente esta identificación, pues la costa en general, pero particularmente la Costa Occidental, vienen experimentando procesos de modernización y dinamismo por los que se ha convertido en un corredor urbano cuya influencia alcanza ahora a los municipios rurales de su entorno.

b) Otro rasgo destacado es referente a la comarca de Ronda, por su inclusión muy alta en los dos clústeres que antes han sido señalados como los conglomerados de rasgos más negativo: el 5 ("estatus demográfico muy negativo con transformación productiva y ligero dinamismo") y con el 3 ("estructura de actividad transformada con envejecimiento y sin dinamismo"). Son dos modelos diferentes, pero en la comarca de Ronda se pueden interpretar bajo las mismas claves: el declive histórico de sus poblaciones (con claro envejecimiento, más o menos severo) y la reducción progresiva de la actividad agraria como actividad inductora. Las diferencias entre ambos modelos en lo que se refiere a dinamismo local, son un mero matiz y, como también se ha dicho, de poco significado por tratarse de puntuaciones bajas y en poblaciones de pocos habitantes, como es el caso de esta comarca.

c) Es también interesante que la comarca de Antequera se identifique principalmente con el clúster 7 "sin transformación productiva y buen estatus demográfico", no porque sea el modelo único que define la comarca (tiene municipios de otros agrupamientos), sino porque es el más numeroso y el que responde a las claves de la permanencia de espacios rurales de bases agrarias con una relativa estabilidad demográfica que, como se apuntó anteriormente, no es un modelo demasiado común en la provincia, y denota la estabilidad agraria de esta zona de la provincia.

d) Otro rasgo territorialmente interesante es cómo la comarca del Valle del Guadalhorce presenta un cuadro de localidades rurales poco uniforme pero coincidentes en la ausencia de dinamismo local, que se ubican tras la orla periurbana que experimenta una profunda transformación como espacio residencial con poblaciones de más de 20000 habitantes. Ausencia de dinamismo local que puede interpretarse como si los avances de la periurbanización estuvieran ya espacialmente contenidos. 
Tabla 16. Proporción de municipios de cada comarca incluidos en cada conglomerado

\begin{tabular}{|c|c|c|c|c|c|c|c|c|}
\hline Clústeres & Descripción & $\begin{array}{l}\frac{\pi}{0} \\
\frac{0}{2} \\
\frac{\Phi}{2} \\
\frac{d}{4}\end{array}$ & $\begin{array}{l}\frac{\pi}{0} \\
0 \\
0 \\
\alpha\end{array}$ & 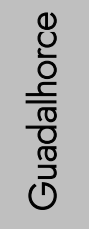 & $\begin{array}{l}\frac{\pi}{3} \\
\frac{0}{0} \\
\frac{0}{0} \\
\frac{x}{4}\end{array}$ & $\begin{array}{l}\frac{\dot{0}}{0} \\
0 \\
0 \\
\frac{\pi}{4} \\
0\end{array}$ & 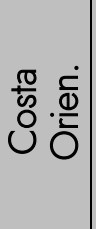 & $\begin{array}{l}\cdot \frac{\pi}{0} \\
\cdot \frac{0}{2} \\
\frac{0}{2}\end{array}$ \\
\hline 1 y 2 & $\begin{array}{c}\text { Estructura de actividad muy transformada, buen } \\
\text { estatus demográfico y dinámicos }\end{array}$ & 0 & 0 & 0 & 0 & 100 & 50 & 8,3 \\
\hline 4 & $\begin{array}{c}\text { Estructura de actividad transformada con buen } \\
\text { estatus demográfico sin dinamismo }\end{array}$ & 14,3 & 9,1 & 41,7 & 4,5 & 0 & 0 & 13,1 \\
\hline 7 & $\begin{array}{c}\text { Estructura de actividad no transformada y buen } \\
\text { estatus demográfico }\end{array}$ & 42,9 & 0 & 0 & 18,2 & 0 & 50 & 16,7 \\
\hline 8 & $\begin{array}{l}\text { Medio bajo (-) en estructura de actividad, en } \\
\text { dinamismo y en estatus demográfico }\end{array}$ & 14,3 & 22,7 & 41,7 & 31,8 & 0 & 0 & 23,8 \\
\hline 6 & $\begin{array}{l}\text { Estructura de actividad no transformada, estatus } \\
\text { demográfico negativo con ligero dinamismo }\end{array}$ & 23,8 & 9,1 & 0 & 27,3 & 0 & 0 & 15,5 \\
\hline 5 & $\begin{array}{l}\text { Estatus demográfico muy negativo con } \\
\text { transformación productiva y ligero dinamismo }\end{array}$ & 4,8 & 36,4 & 0 & 13,6 & 0 & 0 & 14,3 \\
\hline 3 & $\begin{array}{c}\text { Estructura de actividad muy transformada, estatus } \\
\text { demográfico negativo y sin dinamismo }\end{array}$ & 0 & 22,7 & 16,7 & 0 & 0 & 0 & 8,3 \\
\hline & & 100 & 100 & 100 & 100 & 100 & 100 & 100 \\
\hline
\end{tabular}

Fuente: elaboración propia a partir del Censo Población (IECA, 2011)

y de las Estadísticas del MESS (Ministerio de Empleo y Seguridad Social, 2012-2017)

Es una conjetura que se desprende de los modelos dominantes. El $80 \%$ de sus términos se distribuyen por igual entre dos clúster: el clúster 8 que es el intermedio ("medio bajo en transformación productiva, dinamismo o estatus demográfico"), de rasgos negativos poco acusados, y en el clúster 4 ("estructura de actividad transformada con buen estatus demográfico sin dinamismo") que resulta de un gran significado dentro del Valle, prueba de sus ricas bases agrarias que dieron origen en sus pueblos grandes a una notable diversificación productiva (Álora se señaló como el prototipo del grupo) que han ido quedando estancados.

e) Las dos comarcas restantes, la Axarquía y la Costa Oriental, su litoral, destacan por su menor identificación con algún modelo de clúster concreto. En el caso de la comarca de la Axarquía es precisamente la multiplicidad de modelos lo que la hace más singular. El grupo con más miembros en la comarca es el clúster 8, el intermedio, de rasgos negativos poco acusados, y le sigue el 6 ("estructura de actividad no transformada, estatus demográfico negativo con ligero dinamismo"). Por comparación con la comarca serrana de Ronda, el cuadro de diferencias más amplio y de 
modelos menos negativos a pesar de tratarse también de poblaciones pequeñas, es coherente con la peculiaridad de este otro medio montañoso, de igual declive histórico, pero con actividades agrarias puntualmente renovadas (frutales por ejemplo) y conectados al dinamismo de su litoral. En él sólo restan dos municipios de menos de 20000 habitantes. Uno (Torrox) se incluye en el clúster 2 como el litoral en general, y el otro (Algarrobo) se asimila a otros términos de la Axarquía clasificados en el 7 "sin transformación productiva y buen estatus demográfico".

\section{Comparación de las clasificaciones}

El objeto de presentar soluciones de clasificación diferentes es lógicamente su comparación y evaluación. Los resultados de cada una ya han sido examinandos y cualquiera de ellas, salvo la sistemática de 18 tipos por su excesiva fragmentación, ofrece con sus respectivos agrupamientos una perspectiva bastante clara de los modelos a distinguir y de su coherencia con las características geográficas del espacio provincial.

La forma más directa y primaria de establecer la equivalencia entre ambas clasificaciones es descender al análisis de cómo cada municipio se posiciona en ambas. El resultado se presenta a observación gráficamente en el diagrama de Venn (Figura 7).

\section{Figura 7. Comparación entre las clasificaciones}

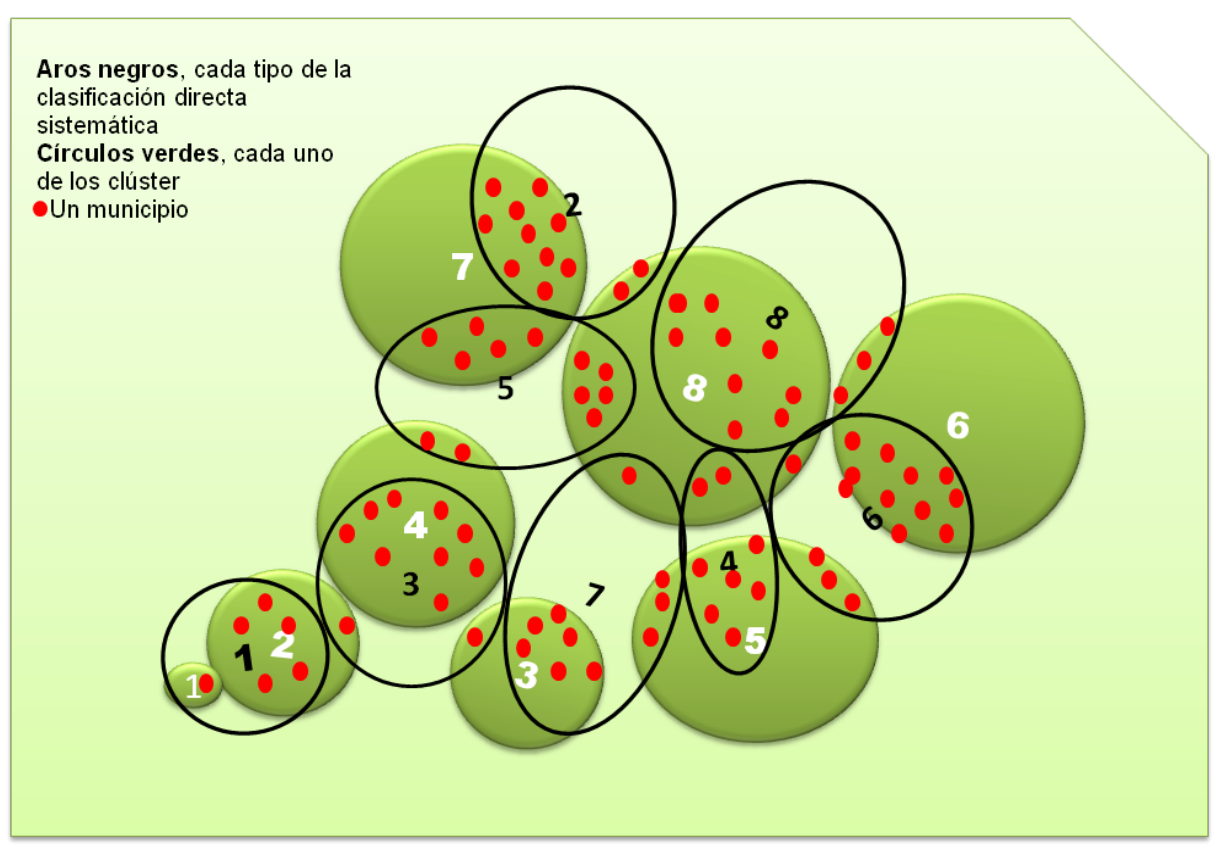

Fuente: elaboración propia

En esta superposición se advierte la existencia de muchas coincidencias fundamentales, que se hacen visibles en las intersecciones con mayor número de elementos (en negrita los clústeres y cursiva las clases, serían: $8 \cap 8,6 \cap 6,4 \cap 3,7 \cap 2,5 \cap 4,3 \cap 7,1 \cap 1,2 \cap 1$, etc.), pero la existencia de 
otras intersecciones de pocos miembros desprende una impresión de variabilidad difícil de eludir si se desciende a comparar individuos en lugar de grupos.

El problema es que existe una dificultad natural para comparar directamente los clúster con los tipos de la clasificación directa. Radica ésta en que los miembros de un clúster se aglutinan en torno a un valor central y no pueden delimitarse por umbrales precisos, al contrario que en las clasificaciones directas, donde cada clase está definida por unos límites precisos en los valores de las variables.

Para reducir a un común denominador los resultados de los dos sistemas, no pudiendo establecer los límites de los clúster se ha recurrido a tratar los tipos de la clasificación directa como un aglomerado, calculándoles el valor medio de cada factor en cada uno de ellos, de modo que este valor central pueda ser comparado con el correspondiente de cada clúster.

La Tabla 17 recoge este ejercicio de comparación. En ella se han ordenado los clúster y los tipos de la clasificación directa haciendo coincidir los tipos más afines entre sí de acuerdo a sus valores de los tres factores. El resultado es muy interesante en el objetivo de este análisis. Se comprueba que cada clúster se identifica claramente con un tipo de la clasificación directa. ${ }^{10}$ La única discordancia se refiere al tipo 5 de la clasificación directa $(--+)$ que no tiene una equivalencia similar a los demás con un clúster, por lo que se ha asimilado por parecido con el clúster 7, cuyo equivalente real en la clasificación es el tipo 2. De ello, la conclusión más satisfactoria es que, sobre la base de los valores medios de cada grupo, ambas clasificaciones descomponen la realidad en modelos muy similares, lo cual es una confirmación de que las diferencias de base entre estos municipios están bien descritas en cualquiera de ellas.

Vista esta coincidencia básica, se ha buscado valorar el grado de homogeneidad que presentan los agrupamientos de cada metodología. De partida cabe esperar un mejor resultado del análisis clúster, porque en su procedimiento se incluye optimizar la homogeneidad intragrupo, mientras que en la clasificación directa, la homogeneidad no está garantizada nada más que por la mayor o menor amplitud de los intervalos de clases.

10 Recuérdese la anomalía del clúster 1, originado por Benahavís, que se vio la oportunidad de fundirlo con el clúster dos, cuyo conjunto coincide plenamente con un tipo (el 1) de la clasificación directa. 
Tabla 17. Valores medios de los clúster y los tipos de la clasificación directa

\begin{tabular}{|c|c|c|c|c|c|c|c|c|c|}
\hline \multicolumn{5}{|r|}{ Clústeres } & \multicolumn{5}{|c|}{ Directa (sistemática) } \\
\hline \multirow{2}{*}{$\mathrm{N}^{\circ}$} & \multicolumn{3}{|c|}{$\begin{array}{c}\text { Valores medios de } \\
\text { los factores }\end{array}$} & \multirow{2}{*}{ Descripción } & \multirow{2}{*}{$\mathrm{N}^{\circ}$} & \multicolumn{3}{|c|}{$\begin{array}{l}\text { Valores medios de } \\
\text { los factores }\end{array}$} & \multirow{2}{*}{ Descripción } \\
\hline & F1 & F3 & F2 & & & $\mathrm{F} 1$ & F3 & F2 & \\
\hline 1 & 1,41 & 7,02 & 1,15 & $\begin{array}{c}\text { Estructura de actividad } \\
\text { transformada, muy dinámicos, } \\
\text { y buen estatus demográfico }\end{array}$ & \multirow{2}{*}{1} & \multirow{2}{*}{1,30} & \multirow{2}{*}{1,68} & \multirow{2}{*}{1,27} & \multirow{2}{*}{$\begin{array}{c}\text { Estructura de actividad } \\
\text { transformada, dinamismo loca } \\
\text { positivo y buen estatus } \\
\text { demográfico }\end{array}$} \\
\hline 2 & 1,36 & 0,48 & 1,20 & $\begin{array}{l}\text { Estructura de actividad } \\
\text { transformada, dinámicos, y } \\
\text { buen estatus demográfico }\end{array}$ & & & & & \\
\hline 3 & 1,48 & $-0,62$ & $-0,39$ & $\begin{array}{l}\text { Estructura de actividad muy } \\
\text { transformada, sin dinamismo y } \\
\text { estatus demográfico negativo }\end{array}$ & 7 & 1,35 & $-0,56$ & $-0,84$ & $\begin{array}{c}\text { Estructura de actividad } \\
\text { transformada, dinamismo loca } \\
\text { negativo y estatus } \\
\text { demográfico negativo }\end{array}$ \\
\hline 4 & 0,65 & $-0,82$ & 0,97 & $\begin{array}{c}\text { Estructura de actividad } \\
\text { transformada, sin dinamismo, } \\
\text { con buen estatus demográfico }\end{array}$ & 3 & 0,89 & $-0,79$ & 0,85 & $\begin{array}{c}\text { Estructura de actividad } \\
\text { transformada, sin dinamismo } \\
\text { local positivo y buen estatus } \\
\text { demográfico }\end{array}$ \\
\hline 5 & 0,54 & 0,37 & $-1,39$ & $\begin{array}{c}\text { Estatus demográfico muy } \\
\text { negativo con estructura de } \\
\text { actividad transformada y ligero } \\
\text { dinamismo }\end{array}$ & 4 & 0,60 & 0,57 & $-1,05$ & $\begin{array}{c}\text { Estructura de actividad } \\
\text { transformada, dinamismo loca } \\
\text { positivo y estatus demográfico } \\
\text { negativo }\end{array}$ \\
\hline 6 & $-1,07$ & 0,37 & $-0,77$ & $\begin{array}{c}\text { Estructura de actividad no } \\
\text { transformada, ligero dinamismo } \\
\text { y estatus demográfico negativo }\end{array}$ & 6 & $-0,84$ & 0,52 & $-0,82$ & $\begin{array}{c}\text { Estructura de actividad no } \\
\text { transformada, dinamismo loca } \\
\text { positivo y estatus } \\
\text { demográfico negativo }\end{array}$ \\
\hline \multirow{2}{*}{7} & \multirow{2}{*}{$-1,07$} & \multirow{2}{*}{0,12} & \multirow{2}{*}{0,90} & \multirow{2}{*}{$\begin{array}{l}\text { Estructura de actividad no } \\
\text { transformada sin dinamismo y } \\
\text { buen estatus demográfico. }\end{array}$} & 2 & $-0,78$ & 0,29 & 0,76 & $\begin{array}{c}\text { Estructura de actividad no } \\
\text { transformada, dinamismo loca } \\
\text { positivo y buen estatus } \\
\text { demográfico }\end{array}$ \\
\hline & & & & & 5 & $-0,67$ & $-0,31$ & 0,69 & $\begin{array}{c}\text { Estructura de actividad no } \\
\text { transformada, dinamismo loca } \\
\text { negativo y buen estatus } \\
\text { demográfico }\end{array}$ \\
\hline 8 & $-0,24$ & $-0,37$ & $-0,11$ & $\begin{array}{c}\text { Medio bajo (-)en estructura de } \\
\text { actividad transformada, } \\
\text { dinamismo local o estatus } \\
\text { demográfico }\end{array}$ & 8 & $-0,49$ & $-0,60$ & $-0,48$ & $\begin{array}{c}\text { Estructura de actividad no } \\
\text { transformada, dinamismo loca } \\
\text { negativo y estatus } \\
\text { demográfico negativo }\end{array}$ \\
\hline
\end{tabular}

Fuente: elaboración propia a partir del Censo Población (IECA, 2011)

y de las Estadísticas del MESS (Ministerio de Empleo y Seguridad Social, 2012-2017) 
Para esta comprobación se han adoptado dos medidas de distancia, la media y la extrema, en cada clase o clúster. No es natural aplicar tales mediciones a los grupos obtenidos de clasificaciones sistemáticas con intervalos de clases conocidos, pero en cualquier caso se pueden calcular igualmente adoptando como centro de las clases los valores medios antes comentados. Para el primer indicador se ha calculado la distancia de cada individuo respecto a los valores medios de las puntuaciones de su grupo, y después se ha hecho la media de las mismas. Para el segundo indicador se ha calculado la matriz de distancia de todos los individuos, para poder seleccionar el valor más elevado contenido en cada una de las clases. El resultado (Tabla 18) nos corrobora la mayor homogeneidad de los clústeres, y también bajo este ángulo las dos clasificaciones aparecen muy igualadas.

Tabla 18. Medidas de distancia intragrupo

\begin{tabular}{|c|c|c|c|c|c|}
\hline \multirow{2}{*}{$\begin{array}{l}\text { Análisis } \\
\text { clúster }\end{array}$} & \multicolumn{2}{|c|}{$\begin{array}{l}\text { Distancia al valor } \\
\text { medio de cada } \\
\text { clúster }\end{array}$} & \multirow{2}{*}{$\begin{array}{c}\text { Clasificación } \\
\text { directa }\end{array}$} & \multicolumn{2}{|c|}{$\begin{array}{c}\text { Distancia al valor } \\
\text { medio de cada } \\
\text { clase }\end{array}$} \\
\hline & Media & Máxima & & Media & Máxima \\
\hline Clúster 1 & 0 & 0,00 & \multirow{2}{*}{ Clase 1} & \multirow{2}{*}{1,99} & \multirow{2}{*}{2,67} \\
\hline Clúster 2 & 1,23 & 1,05 & & & \\
\hline Clúster 3 & 1,04 & 0,93 & Clase 7 & 0,90 & 1,11 \\
\hline Clúster 4 & 0,76 & 0,98 & Clase 3 & 0,76 & 0,99 \\
\hline Clúster 5 & 0,93 & 1,15 & Clase 4 & 0,89 & 1,19 \\
\hline Clúster 6 & 1,86 & 1,17 & Clase 6 & 0,72 & 1,26 \\
\hline \multirow{2}{*}{ Clúster 7} & \multirow{2}{*}{1,6} & \multirow{2}{*}{1,29} & Clase 2 & 0,62 & 0,88 \\
\hline & & & Clase 5 & 0,82 & 1,23 \\
\hline Clúster 8 & 0,77 & 0,85 & Clase 8 & 0,50 & 0,68 \\
\hline
\end{tabular}

Fuente: elaboración propia a partir del Censo Población (IECA, 2011)

y de las Estadísticas del MESS (Ministerio de Empleo y Seguridad Social, 2012-2017)

El ejercicio de comparación no pretende decidir sobre la superioridad de una u otra metodología, sino sencillamente sobre los resultados obtenidos en este análisis concreto por cada una de ellas: La conclusión es que con cualquiera de ellas se describe acertadamente el espectro de diferencias básicas que ofrecen en el momento actual el medio rural de la provincia y, lo que es más importante, la coincidencia básica entre ellas a pesar de las diferencias metodológicas. 


\section{Conclusión}

Durante mucho tiempo el medio rural ha sido definido de forma simplista por oposición a lo urbano y con ello, los métodos de análisis estaban basados en indicadores simples prioritariamente cuantitativos como el volumen y densidad de población; sin embargo a partir de la segunda mitad del siglo XX, las transformaciones acaecidas en el espacio rural, ponen de manifiesto lo limitado que resulta medir una realidad tan compleja como lo rural en base a un solo componente (Ocaña \& Sánchez, 2005). En respuesta a ello, los nuevos análisis han ido incorporando el carácter multidimensional de la ruralidad y su diversidad espacial. Ello ha llevado a un replanteamiento metodológico para la identificación y estimación de lo rural, con la propuesta de algunos autores de índices más precisos y complejos, en los que se asigna una ponderación a cada una de las variables; otros autores han propuesto técnicas multivariantes para encontrar los factores que definan la ruralidad, y en esta línea se sitúa el ejercicio desarrollado en este trabajo.

El objetivo central ha sido realizar una propuesta de tipificación a escala local que conecta con recientes metodologías de delimitación de los espacios rurales desarrolladas en diversas instituciones y centros de investigación europeos, en las que se incorporan otras variables además de las demográficas

En concreto el análisis factorial ha identificado tres factores, dimensiones que diferencian la ruralidad en base a la transformación productiva, y el dinamismo tanto demográfico como económico.

Posteriormente se han propuesto dos sistemas de clasificación, uno estadístico (análisis clúster) y otro de carácter directo, que han coincidido en la determinación de 8 clases.

Queremos subrayar que el éxito de este proceso reside en la validez de la aplicación del análisis multivariante, que sólo se garantiza con el conocimiento de las variables y una correcta selección de éstas para su inclusión en el mismo. Un proceso que indudablemente depende de la disponibilidad de los datos y de su correcta obtención por parte de los organismos competentes.

El análisis ha mostrado que ambas clasificaciones describen acertadamente el espectro de diferencias básicas que ofrece en la actualidad el medio rural de la provincia malagueña y que las dos muestran un alto nivel de coincidencia a pesar de su diferente proceso de ejecución. Ello confirma la existencia objetiva de unos determinados modelos a los que se puede reducir la diversidad de las individualidades municipales para describir los distintos perfiles de los términos rurales en este momento, según los tres criterios que el análisis factorial ha identificado: transformación, estatus demográfico y dinamismo local.

A un nivel de mayor concreción, en la aplicación de la metodología en es espacio rural de la provincia de Málaga, varios aspectos hay que destacar: 
- La dinámica de los municipios responde a dos procesos generales: por un lado, la estabilidad de los pueblos que gozan de buenos recursos agrarios y por otro la continuación del declive de los pequeños municipios serranos con unas escasas bases agrarias.

- La menor dependencia agraria de algunos pequeños municipios, tradicionalmente catalogados como "rural profundo", que se reconocen en la montaña, a los que se une un leve dinamismo reorientado hacia actividades de servicios (básicos para la población, transporte, turísticos...), que responde a su efecto sobre poblaciones muy débiles en número.

- No es una regla general la coincidencia de la dependencia agraria y el bajo dinamismo local, pero frecuentemente convergen.

- La mayor evolución y progreso se produce únicamente cuando convergen las puntuaciones positivas del Factor 1 (Transformación productiva) y el Factor 3 (dinamismo local).

Estas consideraciones abren el camino a prestar atención sobre la importancia en determinados espacios rurales de los ingresos no productivos y ayudas sociales, y a la necesidad de estudiar las fuentes estadísticas que puedan aportar información y por tanto utilizarse para su inclusión en este tipo de análisis de la ruralidad. Una línea de investigación que estamos explorando en la actualidad.

Al seleccionar en Málaga municipios de menos de 20000 habitantes, ha quedado fuera del universo de análisis no solo las ciudades turísticas sino los municipios que ejemplificaron las transformaciones periurbanas del espacio rural hasta finales del siglo XX; de modo que los mayores contrastes entre los pueblos que se reconocían hace un par de décadas y que procedían de la irradiación urbana (periurbanización y desarrollos urbano-turísticos) no han aparecido en el momento actual. En consecuencia (salvo alguna excepción litoral) aparece un cuadro de contrastes más sutil y ligado a factores de naturaleza endógena.

Agradecimientos: Queremos expresar y reconocer la gran oportunidad que ha supuesto para las/os autoras/es de este trabajo el haber contado con las enseñanzas y la guía de la doctora Ocaña Ocaña, M.C. en su fructífera trayectoria universitaria en Málaga. Estaremos siempre infinitamente agradecidas por su labor docente y de investigación que nos abrió el camino hacia nuestro presente profesional, pero sobre todo queremos mostrar nuestra gratitud por la humanidad y generosidad de la que ha hecho gala siempre a lo largo de nuestro camino en común, y que también se ha convertido para nosotras en un referente. Una gratitud que debemos extender a su acertada orientación y crítica en la elaboración de este trabajo.

Declaración responsable: Las/os autoras/es declaran que no existe ningún conflicto de interés con relación a la publicación de este artículo. Las/os autoras/es han contribuido por igual en la realización de las diferentes tareas realizadas. Remedios Larrubia Vargas ha desarrollado, además, la función de coordinación de todos los análisis y valoraciones del artículo para su publicación. 


\section{Bibliografía}

Anderson, T. W. (1984). An introduction to multivariate statistical analysis. New York: Wiley.

Armas Quinta, F.X., Macía Arce, F.X. (2017). Reflexiones acerca de la delimitación y definición del medio rural. Diseño de un índice de ruralidad para Galicia. Finisterra, LII(106), 85-101

Ballas, D., Kalogeresis,T., \& Labrianidis, L. (2003). A comparative study of typologies for rural areas in Europe. Paper submitted to the $43^{\text {rd }}$ European Congress of the Regional Science Association. Jyväskylä, Finland. Retrieved from

https://www.econstor.eu/bitstream/10419/116230/1/ERSA2003_515.pdf

Barnett, S., Roderick, P., Martin, D., \& Diamond, I. (2001) A multilevel analysis of the effects of rurality and social deprivation on premature limiting long term illness. Journal of Epidemiology and Community Health, 55(1), 44-51.

Bauer, G. \& Roux, J. M. (1976). La rurbanisation ou la ville èparpille. Paris: Seuil.

Bericat Alastuey, E. (1993). La teoría del vacío rural. In Consejería de Agricultura y Pesca. In Junta de Andalucía (Eds.), El desarrollo rural a las puertas del siglo XXI (pp. 45-54). Sevilla: Junta de Andalucía.

Bibby, P., \& Shepherd, J. (2004). Developing a new classification of urban and rural areas for policy purposes. the methodology. London: Department for Environment, Food and Rural Affairs.

Brezzi, M., Dilkstra, \& Ruiz, V. (2011). OECD Extended Regional Typology. The economic performance of remote rural regions [OECD Regional Development Working Papers 2011/06]. Retrieved from http://www.oecd.org/cfe/regional-policy/48670214.pdf

Camarero. L. A. (Coord.) (2009). La población rural de España. De los desequilibrios a la sostenibilidad social. Fundaxión La Caixa.

Cáritas Española (Coord.) (2015). Pobreza, privación y desigualdad en el ámbito rural. Fundación Foesa.

Cloke, P. J. (1977). An index of rurality for England and Wales. Regional Studies, 11, 143-152.

Clout, H. (1993). European exprerience of rural development. London: Rural Development Commission.

Comisión Europea (1988). El futuro del mundo rural. Comunicación de la Comisión Europea al Consejo y al Parlamento Europeo del 29 de Julio de 1988, COM (88)501. Boletín de la Comunidad Europea, suplemento $n^{\circ}$ 4/88. Luxemburgo. Oficina de las Publicaciones oficiales de la Unión Europea. 
Consejo Económico y Social de España (CESE) (2018). Informe: El medio rural y su vertebración social $y$ territorial (Report). Retrieved from http://www.ces.es/documents/10180/5461461/Inf0118.pdf

Consejo para el Medio Rural (2009). Primer Programa de Desarrollo rural sostenible (20102014). Criterios comunes para la clasificación de las zonas rurales. Retrieved from hitp://www.mapama.gob.es/es/desarrollo-rural/planes-y-estrategias/ley-para-el-desarrollosostenible-del-medio-rural/prog-desarrollo-rural-sostenible/

Dinis, A. (2006). Marketing and innovation: Useful tools for competitiveness in rural and peripheral áreas. European Planning Studies, 14(1), 9-22.

Echeverri Perico, R., \& Ribero, M.P. (2002). Nueva ruralidad: visión del territorio en América Latina y el Caribe. Ciudad del Saber. Panamá: CIDER/IICA.

Esparcia, J. (2012). Evolución reciente, situación actual y perspectivas futuras en el desarrollo rural en España y en la UE. Retrieved from https://es.scribd.com/document/317227642/EsparciaDes-Rural-Perspectiva-Historia-y-de-Futuro-2012-pdf

ESPON (2007). Urban-rural relations in Europe. ESPON 1.1.2. Final Report. ESPON 2000-2006 Program (Ed. by C. Bengs \& K. Schmidt Thomé). Comisión Europea \& ESPON Monitoring Committee.

Eurostat (2010). A revised urban-rural typology (Eurostat Statistical Books, KS-HA-10-001). Retrieved from hitp://ec.europa.eu/eurostat/web/products-statistical-books/-/KS-HA-10-001-15

Eurostat (2012). The new degree of urbanization. Retrieved from hitps://ec.europa.eu/eurostat/statisticsexplained/index.php/Degree of urbanisation_classification_-2011_revision

Faiguenbaum, S. (2011). Definiciones oficiales de "rural" y/o "urbano" en el mundo. In Dirven et al. (Dir.), Hacia una nueva definición de "rural" con fines estadísticos en América Latina. Santiago de Chile: CEPAL.

Franco, F. (2015). Mundo, Medio y Territorio Rural (Spanish Report). Fundación Encuentro.

García Ramón, M.D., \& Valdovinos Perdices, N . (1995). Geografía rural. Madrid: Síntesis.

Goerlich, F.J., \& Cantarino, I. (2012). Un grid de densidad poblacional para España. Bilbao: Fundación BBVA.

Goerlich, F.J., Reig, E., \& Cantarino, I. (2016). Delimitación y caracterización de las áreas rurales españolas. Presented at the International Conference on Regional Science: Treinta años de integración en Europa desde la perspectiva regional: balance y nuevos retos. XII Reunión de Estudios Regionales. 
Halfacree, K. (1995). Talking about rurality: social representations of the rural as expressed by residents of six English parishes. Journal of Rural Studies, 11(1), 1-20.

INE (Instituto Nacional de Estadística) (2011). Proyecto de los censos demográficos 2011. Madrid: Subdirección General de Estadística.

Johson J.H (1977). Multivariate statistiques analysis in Geography. London: Longman.

Jornad, F., Lambotte, M., Ramos, F., Terres, J.M., \& Bamps, C. (2009). Delimitations of rural areas in Europe using criteria of population density, remoteness and land cover (IRC Scientific and Technical, EUR23757EN).

Larrubia Vargas, R. (1998). El espacio rural: concepto y realidad geográfica. Baetica, 20, 77-95. Lois González, R. C. (2014). As transformacións recentes nun rural galego que mudou. In P. Saavedra Fernández \& R. Rodríguez González (Dirs.), A terra en Galicia: pasado presente e futuro (pp. 112-137). Granada: Universidad Internacional Menéndez Pelayo y Lalín, Concello de Lalín.

López González, F. J., Crecente Maseda, R., \& Miranda Barros, D. (2004). Caracterización rural de los municipios gallegos de cara a una acertada aplicación de iniciativas comunitarias de desarrollo rural. Bilbao: Congreso Internacional de Ingeniería de Proyectos

López Ratón, M., \& Santiago Pérez, M. I. (2005). Construcción de un índice de ruralidad y clasicación de los municipios gallegos. Presented at the I Congresso de Estatística e Investigação Operacional da Galiza e Norte de Portugal.

Márquez Fernández, D. (Coord). (2002). Nuevos horizontes en el desarrollo rural. Madrid: Akal.

Ocaña Ocaña, M.C. (1993). Los municipios rurales andaluces. Población, urbanización y actividad. Boletín Económico de Andalucía, 16, 31-44.

Ocaña Riola R., \& Sánchez Cantalejo, C. (2005) Rurality index for small areas in Spain. Social Indicators Research, 73, 247-266.

OCDE (1988). Nuevas tendencias en polífica rural. Madrid: ITUR, MOPU.

OCDE (1994). Creating rural indicators for shaping territorial policy. Paris: OCDE.

OCDE (2010). OECE Regional Typology. Paris. Retrieved from hitp://www.oecd.org/cfe/regional-policy/48670214.pdf

ONU (1998). Principios y recomendaciones para los censos de población y habitación. New York: ONU.

Pietro Lara, E., \& Ocaña Riola, R. (2010). Updating rurality index for small areas in Spain. Social Indicators Research, 95, 267-286 
Reig Martínez. E., Goerlich Gisbert, F.J., \& Cantarino Martí, I (2016). Delimitación de áreas rurales y urbanas a nivel local. Demografía, coberturas del suelo y accesibilidad. Bilbao: Fundación BBVA. Retrieved from

\section{http://www.grupobbva.com/TLFU/dat/DE_2016_IVIE_delimitacion_areas_rurales.pdf}

Rodríguez Pascual, A.F., Martín-Asín López, G., \& Astudilo Muñoz, B. (1997). La base cartográfica numérica 1:25000 (BCN25). Mapping, 38, 76-82.

Rye, J.F. (2006). Rural youths'images of the rural. Journal of Rural Studies, 22, 409-421.

Sancho Comíns, J., \& Reinoso Moreno, D (2012). La delimitación del ámbito rural: una cuestión clave en los programas de desarrollo rural. Estudios Geográficos, LXXXIII(273), 599-624.

Sancho Comíns, J., \& Reinoso Moreno, D. (2003). Población y poblamiento rural en España: un primer análisis a la luz del censo de 2001. Serie Geográfica, 11, 163-176.

Sorokin. P.A., \& Zimmerman, C.C. (1929). Principles of Rural-Urban sociology. New York: Henry Holt.

Uriel, E., \& Aldas, J. (2005). Análisis Multivariante Aplicado. Spain: Thomson.

Waldorf, B. (2006). A continuous multi-dimensional measure of rurality: moving beyond threshold measures. Selected. Paper prepared for presentation at the American Agricultural Economics Association Annual Meeting. Long Island, California, July 24-27. Departament of Agricultural Economics, Purdue University, West Lafayette, IN, USA. Retrieved from

https://www.pcrd.purdue.edu/files/media/Measuring-Rurality.pdf

Vázquez, I., Sineiro, F., \& Lorenzana, R. (2008). Tipología de municipios rurales de Galicia por indicadores socioeconómicos. Presented at the 12th International Conference on Project Engineering. Retrieved from http://www.usc.es/ecoagra/arquivos//Zaragoza_2008.pdf

Weber, M. (1966). Order in diversity: community without propinquity. In I. Wing (Coord.), Cities: a space. Baltimore: John Hopkins Press. 
Anexo 1a. Municipios incluidos en cada categoría de la clasificación directa

\begin{tabular}{|c|c|c|c|c|c|c|c|}
\hline Clase 1 & Clase 2 & Clase 3 & Clase 4 & Clase 5 & Clase 6 & Clase 7 & Clase 8 \\
\hline $\begin{array}{ccc}\text { F1 } & \text { F3 } & \text { F2 } \\
+ & + & +\end{array}$ & $\begin{array}{l}\text { F1 F3 F2 } \\
-+\quad+\end{array}$ & $\begin{array}{l}\text { F1 F3 F2 } \\
+\quad-\quad+\end{array}$ & $\begin{array}{l}\text { F1 F3 F2 } \\
+\quad+\end{array}$ & $\begin{array}{ccc}\text { F1 F3 F2 } \\
- & +\end{array}$ & $\begin{array}{ccc}\text { F1 F3 F2 } \\
- & + & -\end{array}$ & $\begin{array}{lll}\text { F1 F3 F2 } \\
+ & -\end{array}$ & $\begin{array}{ccc}\text { F1 } & \text { F3 } & \text { F2 } \\
- & - & -\end{array}$ \\
\hline $\begin{array}{c}\text { Benahavís } \\
\text { Casares } \\
\text { Frigiliana } \\
\text { Manilva } \\
\text { Ojén } \\
\text { Torrox }\end{array}$ & \begin{tabular}{|c|} 
Alameda \\
Algarrobo \\
Almáchar \\
Almargen \\
Burgo (El) \\
Cuevas Bajas \\
Fuente de \\
Piedra \\
Humilladero \\
Mollina \\
Sierra de \\
Yeguas \\
V. del \\
Trabuco
\end{tabular} & $\begin{array}{c}\text { Almogía } \\
\text { Álora } \\
\text { Arriate } \\
\text { Casabermeja } \\
\text { Casarabonela } \\
\text { Cortes de la } \\
\text { Frontera } \\
\text { Istán } \\
\text { Monda } \\
\text { Pizarra } \\
\text { Totalán } \\
\text { Yunquera }\end{array}$ & $\begin{array}{l}\text { Alcaucín } \\
\text { Atajate } \\
\text { Benadalid } \\
\text { Canillas de } \\
\text { Albaida } \\
\text { Cómpeta } \\
\text { Faraján } \\
\text { Júzcar } \\
\text { Viñuela }\end{array}$ & $\begin{array}{c}\text { Alozaina } \\
\text { Archidona } \\
\text { Ardales } \\
\text { Benamocarra } \\
\text { Campillos } \\
\text { Colmenar } \\
\text { Iznate } \\
\text { Macharaviaya } \\
\text { Moclinejo } \\
\text { Periana } \\
\text { Teba } \\
\text { V. del Rosario }\end{array}$ & $\begin{array}{c}\text { Alfarnate } \\
\text { Alfarnatejo } \\
\text { Árchez } \\
\text { Benamargosa } \\
\text { Comares } \\
\text { Cuevas de San } \\
\text { Marcos } \\
\text { Cútar } \\
\text { Pujerra } \\
\text { Riogordo } \\
\text { Sayalonga } \\
\text { Sedella } \\
\text { V. Algaidas } \\
\text { V. de Tapia }\end{array}$ & $\begin{array}{c}\text { Algatocín } \\
\text { Alpandeire } \\
\text { Benalauría } \\
\text { Benaoján } \\
\text { Gaucín } \\
\text { Genalguacil } \\
\text { Guaro } \\
\text { Jimera de Líbar } \\
\text { Parauta }\end{array}$ & \begin{tabular}{|c} 
Arenas \\
Benarrabá \\
Borge (El) \\
Canillas de \\
Aceituno \\
Cañete la Real \\
Carratraca \\
Cuevas del \\
Becerro \\
lgualeja \\
Jubrique \\
Montejaque \\
Salares \\
Tolox \\
Valle de \\
Abdalajís
\end{tabular} \\
\hline
\end{tabular}

Fuente: elaboración propia a partir de los resultados del análisis factorial 


\section{Anexo 1b. Municipios incluidos en cada conglomerado}

\begin{tabular}{|c|c|c|c|c|c|c|c|}
\hline Cluster A (1) & Cluster B (2) & Cluster C (4) & Cluster D (7) & Cluster E (8) & Cluster F (6) & Cluster G (5) & Cluster H (3) \\
\hline Benahavís & $\begin{array}{c}\text { Frigiliana } \\
\text { Casares } \\
\text { Istán } \\
\text { Manilva } \\
\text { Ojén } \\
\text { Torrox }\end{array}$ & $\begin{array}{c}\text { Campillos } \\
\text { Casabermeja } \\
\text { Colmenar } \\
\text { Arriate } \\
\text { Cortes de la } \\
\text { Frontera } \\
\text { Almogía } \\
\text { Álora } \\
\text { Monda } \\
\text { Pizarra } \\
\text { Yunquera } \\
\text { Totalán }\end{array}$ & \begin{tabular}{|c|} 
Alameda \\
Archidona \\
Cuevas Bajas \\
Fuente de \\
Piedra \\
Humilladero \\
Mollina \\
Sierra de \\
Yeguas \\
Teba \\
Villanueva \\
del Trabuco \\
Almáchar \\
Benamocarra \\
Iznate \\
Periana \\
Algarrobo
\end{tabular} & $\begin{array}{c}\text { Almargen } \\
\text { Riogordo } \\
\text { Villanueva } \\
\text { del Rosario } \\
\text { Benarrabá } \\
\text { Burgo (El) } \\
\text { Cuevas del } \\
\text { Becerro } \\
\text { Jubrique } \\
\text { Montejaque } \\
\text { Alozaina } \\
\text { Ardales } \\
\text { Carratraca } \\
\text { Tolox } \\
\text { Valle de } \\
\text { Abdalajís } \\
\text { Alcaucín } \\
\text { Arenas } \\
\text { Borge (El) } \\
\text { Canillas de } \\
\text { Aceituno } \\
\text { Canillas de } \\
\text { Albaida } \\
\text { Macharaviay } \\
\text { a } \\
\text { Moclinejo }\end{array}$ & $\begin{array}{c}\text { Alfarnate } \\
\text { Cañete la Real } \\
\text { Cuevas de } \\
\text { San Marcos } \\
\text { Villanueva de } \\
\text { Algaidas } \\
\text { Villanueva de } \\
\text { Tapia } \\
\text { lgualeja } \\
\text { Pujerra } \\
\text { Árchez } \\
\text { Benamargosa } \\
\text { Comares } \\
\text { Cútar } \\
\text { Salares } \\
\text { Sayalonga }\end{array}$ & $\begin{array}{c}\text { Alfarnatejo } \\
\text { Alpandeire } \\
\text { Atajate } \\
\text { Benadalid } \\
\text { Benalauría } \\
\text { Cartajima } \\
\text { Faraján } \\
\text { Genalguacil } \\
\text { Júzcar } \\
\text { Cómpeta } \\
\text { Sedella } \\
\text { Viñuela }\end{array}$ & $\begin{array}{c}\text { Algatocín } \\
\text { Benaoján } \\
\text { Gaucín } \\
\text { Jimera de } \\
\text { Líbar } \\
\text { Parauta } \\
\text { Casarabonel } \\
\text { a } \\
\text { Guaro }\end{array}$ \\
\hline
\end{tabular}

Fuente: elaboración propia a partir de los resultados del análisis factorial 